\title{
EL CASO DE POLONIA EN LA UE: RETROCESOS DEMOCRÁTICOS Y DEL ESTADO DE DERECHO $Y$ Y DILEMA DE COPENAGUE»
}

\author{
JUAN FERNANDO LÓPEZ AGUILAR \\ Catedrático de Derecho Constitucional \\ Universidad de Las Palmas de Gran Canaria
}

SUMARIO

I. Introducción: los retrocesos democraticos vistos desde el Parlamento Europeo. II. La crisis de 2008 y su cronificación en la UE. Retrocesos democráticos y nacionalismo rampante. la glaciación europea. III. El caso de Polonia y sus secuelas en la UE: el síndrome de putinización. IV. El caso de Polonia ante el Parlamento Europeo. V. Reflexiones conclusivas: retrocesos democraticos y dilemas de Copenague. El caso de Polonia en contexto.

\section{INTRODUCCIÓN: LOS RETROCESOS DEMOCRATICOS VISTOS DESDE EL PARLAMENTO EUROPEO}

1. El retroceso en los derechos y la democracia en la UE, visto desde el Parlamento Europeo

El Parlamento Europeo (en adelante, PE) —en Pleno y en Comisión, singularmente en la Comisión parlamentaria con competencias en materia de Libertades, Justicia e Interior, llamada Comisión LIBE — ha tratado extensamente el desafío planteado por los alarmantes signos de deterioro y retroceso de la democracia en la UE durante las legislaturas europeas 2009-2014 y 2014-2019. En coincidencia, y no es casual, con la inmersión de la Unión en la peor crisis de su historia. La que arrancó en 2008. La que hemos dado en llamar Gran Recesión de la UE. La glaciación europea.

Es cierto, viene sucediendo, no solamente en Hungría, y más recientemente en Polonia, sino en otras latitudes y longitudes de Europa.

Pero, si cabe afirmar que los retrocesos en la UE acusan desde hace algún tiempo una singular gravedad en lo que algunos comentaristas han dado en lla- 
mar, gráficamente, «putinización» de Hungría, puede afirmarse también que, a partir de la cronificación de la crisis europea, en el curso de poco tiempo se habría pasado rápida e intensamente a lo que bien podría llamarse «orbanización» de Polonia (por Viktor Orban, primer ministro de Hungría desde 2010 con aplastante mayoría de 2/3 en el Parlamento húngaro). Y de ahí a la «bungarización» de otros Estados miembros (en adelante, EE.MM) de un modo u otro afectados por un proceso de recortes de pluralismo informativo y de libertades públicas. Se trata por tanto de un síndrome más extenso y muy inquietante, que, con variable intensidad, viene manifestándose en un espectro creciente de EE.MM de la UE. Y no solo - me reitero- en los de reciente adhesión (la gran ampliación de 2004, con diez países a bordo, 2007, Rumanía y Bulgaria, y 2013, Croacia).

El caso húngaro, en efecto, puede resaltarse como un aldabonazo, puesto que ejemplifica la activación del gatillo de los retrocesos en curso. Ejemplifica esta deriva una sumaria recapitulación de la secuencia de reformas constitucionales puestas en marcha y consumadas en la República de Hungría ${ }^{1}$. Nada menos que cinco en el apretado lapso de 2010-2012, pudiendo sintetizarse en los siguientes alcances:

a) Restricción de la jurisdicción del Tribunal Constitucional;

b) Restricción del alcance de la doctrina jurisprudencial (case Law) del TC en la resolución de casos de transcendencia política;

c) Restricción legal dirigida a reforzar la fijación territorial de los estudiantes restringiendo su movilidad con vistas a su permanencia en Hungría;

d) Restricción de la libertad de expresión en la publicidad político-electoral $y$ en el pluralismo informativo;

e) Reforma constitucional limitativa del Derecho de familia;

f) Criminalización de los «sin techo».

El impacto acumulativo de este paquete de reformas motivó, en su momento, un oportuno e incisivo Informe de la Comisión de Venecia del Consejo de Europa, complementado acto seguido por un contundente Informe de la Helsinki Foundation for Human Rights. Pero, en lo que nos concierne, dio lugar asimismo, como hemos de ver de inmediato, a un específico Informe del PE sobre los derechos fundamentales en Hungría.

\section{El informe del PE sobre Hungría}

Efectivamente, vista la naturaleza polémica de la situación planteada, en 2011 el PE resolvió poner en marcha una delegación (fact finding mission) despla-

1 Véase a este respecto, sobre la apretada secuencia de sucesivas reformas constitucionales impulsadas y completadas por el Gobierno de Fidesz, Csink, Lóránt, SCHAnda, Balázs, Zs.VArga, András: The Basic Law of Hungary: A First Commentary, Clarus Press Ltd, 2012. 
zada a Budapest con el propósito de sostener una interlocución — tan completa y extensa como resultara posible — con las autoridades húngaras ${ }^{2}$.

El objetivo expreso era el de calibrar enteramente la envergadura y detalle de la secuencia de reformas constitucionales entonces puestas en marcha. Pero también, yendo más allá, el de abordar la evaluación de las respuestas de esas autoridades y del Gobierno de Orban a los informes elaborados por la Asamblea Parlamentaria del Consejo de Europa y por la Comisión de Venecia (Venice Commission: Democracy Through Law, organismo del Consejo de Europa para el fortalecimiento del Estado de Derecho, especializado en la promoción de reformas institucionales de la separación de poderes y la protección judicial de los derechos fundamentales) a todo lo largo del curso de sus procedimientos.

Tras esta delegación parlamentaria a Hungría, el Parlamento Europeo elaboró, debatió y adoptó una «Resolución sobre Hungría» (Ponente: Rui Tavares, asumiendo yo mismo la tarea de «ponente alternativo» o Shadow Rapporteur del informe).

Con esa ocasión, tanto la comisión LIBE como el Pleno del PE debatieron extensamente la posible activación del desde entonces llamado «mecanismo de Estado de Derecho» (Rule of Law Mechanism) ${ }^{3}$ y su proyección sobre una eventual aplicación del art. 7 TUE, que incluye la consideración de la consecuencia eventual de retirada del derecho de voto en el Consejo del Estado concernido.

Siguió, con posterioridad, la formulación de una pregunta oral de la Comisión LIBE con debate en Pleno sobre dicha aplicación del «Rule of Law Mechanism» y el art. 7 TUE (diciembre de 2015).

Pues bien, desde entonces, ya en el curso de la actual legislatura europea (2014-2019), han sido reiteradas y múltiples las ocasiones en que la Comisión Europea (la Comisión Juncker, con su vicepresidente Frans Timmermans) se ha caracterizado por un discurso contemporizador, carente de efecto práctico, ante el deterioro de estándares democráticos en los EE.MM de la UE. El mismo discurso, por cierto, practicado por Věra Jourová, la actual comisaria de Justicia y responsable, por tanto, de la Justice Scoreboard ( «marcador» de deterioros de los indicadores de independencia judicial, acceso a la justicia y a un juicio con todas las garantías, instrumento establecido por la Comisión por iniciativa de la entonces Vicepresidenta Vivianne Reding a partir de 2013), cuya ejecutoria en este ámbito dista todavía hoy del compromiso que la situación requiere, a la vista de los hechos, los datos y las polémicas que vamos a analizar.

2 Véase, a este respecto, el informe de la delegación de diputados al Parlamento Europeo sobre su visita a Budapest del 24 al 26 de septiembre de 2012.

3 Véase la Comunicación de la Comisión al Parlamento Europeo y al Consejo: Un nuevo marco de la UE para reforzar el Estado de Derecho (COM/2014/0158 final de 11 de marzo de 2014).

4 Véase la Resolución del Parlamento Europeo, de 16 de diciembre de 2015, sobre la situación en Hungría (2015/2935(RSP). 


\section{LA CRISIS DE 2008 Y SU CRONIFICACIÓN EN LA UE. RETROCESOS DEMOCRÁTICOS Y NACIONALISMO RAMPANTE. LA GLACIACIÓN EUROPEA}

\section{Episodios relevantes de la putinización de Hungría}

La discusión a propósito de la secuencia de reformas constitucionales y legales en Hungría ha tenido lugar en sucesivas ocasiones no sólo en el ámbito del PE y del Consejo de Europa (su Asamblea Parlamentaria y la Comisión de Venecia). En efecto, también, por su parte, la Asamblea Parlamentaria de la OSCE adoptó un dictamen sobre las reformas húngaras. Las principales observaciones contenidas en el Informe de Conclusiones de la OSCE en las elecciones parlamentarias celebradas en Hungría el 6 de abril de $2014^{5}$ resultan no solamente ilustrativas de la coincidencia básica con los planteamientos de los anteriores informes sobre Hungría del PE y del Consejo de Europa en el examen crítico de los problemas planteados, sino, por su magnitud, sencillamente alarmantes. En sus rasgos más sumarios, pueden resumirse como sigue:

En la secuencia descrita por los últimos procesos electorales, el partido de gobierno (Fidesz, una formación de orientación ultranacionalista y ultraconservadora encuadrada en la familia europea del PPE) gozó de «ventajas ilegítimas» en la campaña electoral debidas al intenso «sesgo progubernamental» de la cobertura mediática (en una estructura de medios claramente hegemonizada por los medios públicos controlados por el Gobierno ultraconservador de Orban ${ }^{6}$ ) y la prácticamente inexistente separación entre las estructuras del partido Fidesz y las instituciones del Estado, particularmente aquellas orientadas a ejercer funciones de garantía y de control externo (Ombudsman, Consejo Audiovisual, Presidencia de la Oficina Judicial...).

Se ha asistido, de otro lado, a un progresivo e inexorable desmantelamiento de los más relevantes instrumentos de Checks and Balances (incluida la configuración y utilización masiva de las denominadas leyes «cardinales» —entre otras, las que regulan nada menos que la legislación electoral—, aprobadas por mayoría cualificada y monocolor de Fidesz y varias veces reformadas sin ningún procedimiento que garantice la representación de las minorías y su derecho de enmienda).

Se ha dado paso al establecimiento de un procedimiento parlamentario de mayoría impuesto por el partido ganador en su propio favor; se ha adoptado le-

5 OSCE/ODIHR Limited Election Observation Mission Final Report - Hungary, Parliamentary elections on 6th April 2014 (Varsovia, 11 de julio de 2016): http://www.osce.org/odihr/elections/hungary/121098? download=true

6 Véase la Resolución del Parlamento Europeo, de 10 de marzo de 2011, sobre la Ley de Medios de Comunicación húngara (DO C 199 E de 7.7.2012, p. 154); y el dictamen (2011)10 de 25 de febrero de 2011 del Comisario de Derechos Humanos del Consejo de Europa sobre la legislación relativa a los medios de comunicación a la luz de las normas del Consejo de Europa sobre la libertad de los medios de comunicación, así como las observaciones de 30 de mayo de 2011 del Secretario de Estado húngaro de Comunicación del Gobierno sobre dicho dictamen. 
galmente un procedimiento gubernamental de selección de miembros de la administración electoral; se ha aprobado la reforma legal de la ciudadanía para ensanchar el voto a las minorías húngaras en el exterior y restringir el sufragio a los residentes en el interior; y la «restricción indebida» del pluralismo informativo en los medios audiovisuales.

A estos reproches se suman las consideraciones relevantes del Comisario Europeo de Derechos Humanos del Consejo de Europa, Nils Muižnieks, en su Informe sobre Hungría ${ }^{7}$. Así, este Comisario Europeo del Consejo de Europa expresa su preocupación por el efecto disuasorio de la reforma de los medios sobre el pluralismo informativo; por la intervención regulatoria masiva sobre el Consejo de Medios Comunicación (influencia y control gubernamental de los medios); por las amenazas crecientes contra el pluralismo informativo y la libertad de comunicación; por el incremento inquietante de los episodios concretos y reportados de intolerancia y/o discriminación contra los gitanos (comunidad roma) y judíos, así como de la utilización en los espacios públicos de discursos y retóricas ofensivos contra las minorías; por la tentativa de penalización de la homosexualidad y por el anuncio de prohibición de la Gay Pride March en 2011 y 2012; y por las detenciones irregulares de inmigrantes, refugiados y demandantes de asilo, incluyendo detenciones de menores...

Vino luego una importante (y oportuna) sentencia del TEDH sobre Hungría ${ }^{8}$ Y el correspondiente crescendo reactivo de la retórica de Viktor Orban con una cascada de mantras reiterativos e insistentes:

- Victimismo nacional: «Hungría bajo ataque y asedio»... por la propia $\mathrm{UE}$, el PE, la «extranjería»... los inmigrantes... y los asylum seekers (los demandantes de asilo);

— «Orgullo y restauración», ideas fuerza del discurso del partido en el Gobierno;

— Identificación de «enemigos» de la soberanía húngara: la UE, la «extranjería»... e incluso los demandantes de asilo a partir de la mal llamada «crisis de los refugiados» en 2015;

- Retórica resistencial de la libertad en Hungría en clave «anticomunista», conducente a la expedición de carta blanca a todo tipo de iniciativas reaccionarias y represivas.

Su corolario conduce a la formulación de una filosofía política proclamadamente «antiliberal»: «Democracia iliberal» (vale decir, si cabe, el oxímoron de una idea de «democracia inconstitucional») es el nuevo concepto: reivindicación del antili-

7 Vid., Informe elaborado por Nils Muižnieks, Comisario para los Derechos Humanos del Consejo de Europa, tras su visita a Hungría, del 1 al 4 de julio de 2014: https://www.ecoi.net/file_upload/1226_1421659549_ com-instranet.pdf

8 STEDH de 12 de enero de 2016, en el asunto Zsabó y Vissy/Hungría. 
beralismo como justificación de un demotismo despótico y (tendencialmente) populista. De acuerdo con este discurso, la democracia «sofoca y asfixia»: y abundando en tales tesis, en cambio, la Nación «libera»... y se realza, claro, por la ejecución sin vacilaciones del programa del Partido en el Gobierno. De ahí al «seguritarismo»: exaltación del «orden público»: acallar la disidencia es objetivo explícito de la política gubernamental. Y a la reivindicación del Derecho nacional húngaro a «debatir sobre cualquier asunto, incluso sobre la reinstauración de la pena de muerte» y sobre la eventual convocatoria de sendos referendos para restringir el derecho de los extranjeros y para prohibir la entrada de nuevos inmigrantes».

En este punto procede reseñar además que el actual «representante de Hungría en la Comisión», Tibor Navracsics (ex viceprimer ministro de Hungría con Viktor Orban, ministro de Administraciones Públicas y Justicia, luego ministro de Asuntos Exteriores y Comercio y actualmente Comisario Europeo de Educación, Cultura, Juventud y Deporte) se destacó durante años como uno de los más estrechos colaboradores del Primer Ministro. Como ministro de Justicia llevó adelante las reformas legales más agresivas en materia de reparación de poderes, independencia del Poder Judicial, imparcialidad de jueces y del Ministro Fiscal, derecho al acceso a la justicia y a juez predeterminado por la ley (Lawful Judge). Estableció asimismo una Oficina Judicial (nuevo órgano de gobierno de la administración de Justicia, regida, por cierto, por la esposa del líder del Fidesz en el Partido Popular Europeo (PPE) del PE). Como consecuencia de esas reformas, a juicio de muchos analistas (y desde luego de la oposición), la separación de poderes y el Estado de Derecho habrían llegado a hacerse irreconocibles, en la práctica, en Hungría.

Por su parte, el Fiscal Jefe de la República de Hungría (jefe de la acusación pública y, al tiempo, miembro del Gobierno) ha incoado, desde la aprobación de las reformas comentadas (2012), un centenar de procesamientos de clara intencionalidad y motivación política. Las correspondientes leyes de reforma procesal penal fueron aprobadas sin trámite de discusión parlamentaria. Con ocasión de esas reformas, el TC perdió asimismo buena parte de su jurisdicción, revisora de la constitucionalidad de las leyes.

Baste recordarlo aquí: la actual redacción de la Constitución de Hungría ( $B a$ sic Law de 1949, con 5 enmiendas en 3 años, entre 2010 y 2013) fue adoptada sin consenso, con la mayoría de 2/3 del partido en el Gobierno. La Comisión de Venecia del Consejo de Europa denunció cada uno de sus principales elementos como el estrechamiento de márgenes en la separación entre Iglesia y Estado. La nueva Ley de Medios de Comunicación se adoptó por el mismo método y la misma mayoría, ignorando y despreciando las advertencias de la OSCE y de la Comisión de Venecia: hacia el control gubernamental masivo de los medios de comunicación?.

9 Véase Analysis and assessment of a package of Hungarian legislation and draft legislation on media and telecommunications (Análisis y evaluación de un paquete de leyes y proyectos de ley húngaros sobre los medios de comunicación y las telecomunicaciones), elaborado por Karol Jakubowicz para la OSCE, 2010. 
Además, se aprobó en ese periodo la nueva Ley Electoral (ejemplo de aplicación de la categoría de las «leyes cardinales») favoreciendo al Partido de gobierno (con «premio de mayoría» para reforzar aún más su abrumadora hegemonía). Se estableció asimismo el retiro forzoso de jueces y magistrados no «adictos» al Gobierno de Fidesz. Se reguló la potestad de la Oficina Judicial para transferir casos individuales a jueces (gubernamentales) ajenos a la regla del juez predeterminado por la ley (Lawful Judge), alegando para ello una mera «redistribución de la carga de trabajo». Se multiplicaron los ataques masivos a las ONGs y Think Tanks cuyo trabajo se concentrase en el ámbito de los derechos fundamentales y el pluralismo. Y, como corolario de todo lo anterior, la retórica de Orban ha llegado a propugnar la idea de Hungría como modelo y paradigma de lo que ha dado en llamarse «democracia iliberal»y/o «antiliberal».

\section{El Caso Polonia: desviación de la ruta democrática (los casos de Dinamarca, y, como luego veremos, Reino Unido, Italia... España, y sigue...)}

Como examinaremos más adelante, la coordenada concreta del caso de Polonia en la $U E$ es la de la agudización del llamado «dilema de Copenhague». Se alude con esta expresión, tan propia de la jerga europea, a la contraposición descrita por la exigencia de los llamados «criterios de Copenhague» (por haber sido adoptados por el Consejo celebrado en esa capital bajo Presidencia danesa en 1993) para la adhesión de cualquier Estado candidato a la UE (-Estado de Derecho, democracia representativa, separación de poderes, Justicia independiente, derechos fundamentales y tutela judicial, protección de minorías... y capacidad para incorporar las reglas de la competencia propias del mercado interior-), frente a la inexistencia de medios efectivos para velar por su observancia una vez se ha pasado a formar parte del Club.

En efecto, el planteamiento del llamado «Copenhagen Dilemma» se produce con ocasión del proceso de conformación, tras las elecciones legislativas de septiembre de 2015, de un nuevo gobierno ultraconservador y nacionalista en la República de Polonia. Su líder indiscutido: Jaroslaw Kaczynsky (hemano gemelo de Lech, fallecido en 2010 en accidente de aviación); Primera Ministra: Beata Szydlo. Partido: Ley y Justicia.

La secuencia a partir de ahí describe concomitancias con el precedente caso búngaro. En ambos casos asistimos a la agudización, en corto espacio de tiempo, de una deriva autoritaria que conducirá abiertamente a un «jaque a la propia UE».

Así, como era esperable, se encadenarán en el PE las preocupaciones suscitadas, y los correspondientes debates, acerca de la reforma legislativa del TC polaco; de la restricción del pluralismo informativo y la abrupta regubernamentalización de medios de comunicación públicos y privados; de la activación legislativa de una agenda ultrarreaccionaria en diferentes campos de la legislación civil y 
penal en la República Polaca, y del anuncio de proyectos de reformas constitucionales conducentes a una suerte de «orbanización» de Polonia...

Como hemos de ver más adelante, el sucesivo relato de esos debates en el PE incluye la formulación de una Pregunta oral a la Comisión en Pleno, intervenciones parlamentarias sobre los proyectados desarrollos legislativos en materia de seguridad y medidas antiterroristas; en el ámbito de la restricción de los derechos sexuales y reproductivos; sobre la agenda represiva en diferentes materias de derecho de familia; sobre la discriminación racial, sobre el incremento de delitos de odio/discurso del odio y ataques antisemitas; sobre el denunciado asalto a la separación de poderes e independencia judicial; y sobre la restricción de derechos de personas inmigrantes y refugiados (en el marco de un llamado «Grupo de Visegrado» en comandita con Hungría, República Checa y Eslovaquia).

Por su parte, de la iniciativa de la Comisión Europea de establecer un «diálogo con las autoridades polacas» (enmarcado en el llamado Rule of Law Mechanism, diseñado y operativo desde 2014) se desprende, en primer término, un análisis preliminar del impacto de la política europea en Polonia (política de vecindad con Ucrania incluida; orden y seguridad; niveles de cumplimiento de los establecido el Tratado de Lisboa acerca del Espacio de Libertad, Justicia y Seguridad, Título V TFUE, arts. 68 a 89, especialmente en relación con la reforma legislativa del TC de Polonia), así como, en segundo término, acerca de la evaluación del eventual «efecto contagio» de Polonia sobre otros EE.MM.

La primera conclusión de dicha interlocución de las autoridades polacas con la Comisión Europea no puede resulta sorprendente: de la incorporación decidida del actual gobierno polaco a lo que podemos llamar ola de reaccionarismo defensivo en los EE.MM de la UE sólo cabía esperar una vuelta de tuerca adicional sobre ese estado de cosas que emite desde hace un tiempo un mensaje inquietante en tanto que contundente: «No más Europa». Una expresión de fatiga, por consiguiente, al mismo tiempo, tanto de mayor «ampliación» como de «profundización» en los valores proclamados e en el Tratado de Lisboa (TL).

Pero lo relevante es que el cuadro de referencias comparativas de alarma se expande sucesivamente entre otros EE.MM, no solo entre los fácilmente señalables por su «reciente adhesión» y escasa tradición democrática, puesto que algunos de ellos se caracterizan incluso por el prestigio acumulado de un historial «veterano» en la construcción europea y una sólida radicación de políticas sociales ampliamente identificadas con el modelo europeo.

A título ejemplificativo, baste aquí repasar, siquiera someramente, el contenido de la reciente Ley de Inmigración impulsada por el Gobierno de coalición (liberal conservadora) en Dinamarca, nada menos:

a) Ampliación del periodo temporal para poder acceder a la reunificación familiar (de 1 a 3 años);

b) Restricción de los criterios para obtener residencia permanente en Dinamarca; 
c) Mayor rigidez y automatismo de las reglas para la revocación del permiso de residencia de los refugiados;

d) Confiscación de bienes de los demandantes de asilo para financiar su propia atención;

e) Extensión del lapso temporal (3 meses) en que los demandantes de asilo estén obligados a pagar para cubrir los gastos por si su propia estancia se amplía mientras se tramita la solicitud de protección;

f) Imposición de una tasa para la reunificación familiar y la residencia permanente;

g) Reducción (un 10\%) de los beneficios económicos de los refugiados;

h) Restricción (hasta su desaparición) de las hasta entonces vigentes posibilidades de que los demandantes de asilo puedan alojarse en establecimientos distintos a centros para internamiento de los refugiados;

i) Modificación (restrictiva) del criterio para la elegibilidad de «cuotas nacionales de refugiados» introduciendo el factor de «potencial de integración», y modificación (restrictiva) de los estatutos jurídicos subjetivos de la protección temporal. Sí, Dinamarca, nada menos ${ }^{10} \ldots$

Y de ahí a las propuestas planteadas por el Primer Ministro conservador británico David Cameron con ocasión del referéndum celebrado el 23 de junio de 2016 para decidir acerca de la permanencia o salida del Reino Unido de la UE, sobre cuyas condiciones (asombrosamente asumidas por el Consejo en la negociación conducida por su presidente permanente, el polaco Donald Tusk), por rezumar un carácter notoriamente contraeuropeo, y por lo tanto inaceptable, me he pronunciado también en anteriores escritos...Sabido es el resultado del referéndum celebrado ese 23 de junio. Brexit. Y sucesión de episodios reportados de acoso contra ciudadanos europeos nacionales de otros EE.MM en Reino Unido en los días inmediatamente sucesivos... El Reino Unido, nada menos ${ }^{11}$.

\section{Nacionalismos e intolerancia en Europa: la crisis cronificada, más allá del euro}

Pongamos ahora en contexto el cuadro general de los problemas hasta ahora enunciados o descritos.

A rebufo de la crisis europea desatada en 2008, y sobre todo a resultas de su desastrosa gestión, un inquietante incremento de los delitos motivados por el racismo, la xenofobia, la intolerancia o el prejuicio contra aquellos a quienes se

10 Lopez Aguilar, J F.: «¡Lo que faltaba: Dinamarca!», en Republica.com (28/01/2016).

11 Lopez Aguilar, J F.: «¿Acaso es mejor un mal acuerdo?», en Huffingtonpost.com (24/02/2016); «Unhappy ending» en Huffingtonpost.com (17/06/2016); y «Brexit: (otro) referéndum en el que todos perdemos» en Republica.com (06/04/2016). 
considera «vulnerables» o simplemente diferentes, han emergido y proliferado como expresión de ese fantasma imparable que, parafraseando al Karl Marx del Manifiesto Comunista (1848), está recorriendo Europa: un remake de populismo y nacionalismo rampante ${ }^{12}$.

En efecto, lo que — según en un principio se nos dijo— empezó siendo una crisis originariamente financiera y económica, hace ya mucho tiempo que se transmutó en una profundísima crisis social y en una crisis política que alcanza a toda la UE y afecta corrosivamente a los valores fundacionales de la construcción europea, a su identidad y proyecto. La interminable crisis del euro - $\tan$ catastróficamente manejada, como ejemplifica Grecia de manera paroxística- ha sido - sigue siendo, tristemente- sumamente grave en sí. Pero el deterioro de la democracia y del respeto por los derechos fundamentales en Europa to ha sido - y es- todavía mucho más ${ }^{13}$.

El espectro de la intolerancia, y su desesperada e incesante búsqueda de chivos expiatorios con los que exorcizar el malestar general, se ha desatado, a galope, en nuestro continente. Se manifiesta no sólo mediante la multiplicación de partidos extremistas, formaciones populistas que explotan el resentimiento y frustración acumulada, sino también a través del prejuicio la estigmatización del otro, cada vez más frecuente incluso en partidos que ostentan responsabilidades de gobierno en EE.MM de la UE.

Las causas del populismo son viejas conocidas de Europa: la tentación de abandonarse a la explotación política del miedo, la ansiedad y la pérdida de referencias culturales homogéneas, que son consecuencia a su vez de la diversidad y el pluralismo creciente... ha dado demasiadas veces señales de vida en la historia de nuestro viejo continente. Pero también se ha acompañado en esta concreta ocasión de una lucha, cada vez más encarnizada, por una protección social menguante y amenazada, así como por unos recursos económicos cada vez más escasos en el desdichado contexto de la Gran Recesión y en su posterior desgobierno.

Conjurar tal amenaza requiere, ciertamente, respuestas políticas y medidas normativas, esto es, poner en hora la legislación europea: actualizando los valores fundantes del Convenio Europeo de Derechos Humanos de 1950 (y sus 14 Protocolos), y tomando en serio la entrada en vigor, con el Tratado de Lisboa, de la Carta de los Derechos Fundamentales de la UE (CDFUE). Recuérdese, en este punto, que el mandato de ratificación del Convenio Europeo de Derechos Humanos por parte de la UE (art. 6 TUE) continúa todavía pendiente de cumplimiento tras el desalentador dictamen $2 / 13$ TFUE $^{14}$.

12 Véase Bartlett, J, Birdwell, J, Littler M: The new face of digital populism, Demos, 2011.

13 Lopez Aguilar, J F.: La UE: Suicidio o rescate, Tirant lo Blanch, 2013.

14 Véase el Dictamen 2/13: Dictamen del Tribunal de Justicia (Pleno) de 18 de diciembre de 2014 - Comisión Europea (Dictamen emitido en virtud del artículo 218 TFUE, apartado 11 — Proyecto de acuerdo internacional - Adhesión de la Unión Europea al Convenio Europeo para la Protección de los Derechos Humanos y de las Libertades Fundamentales - Compatibilidad de dicho Proyecto con los Tratados UE 
Por su parte, procede resaltar que el Espacio Europeo de Libertad, Seguridad y Justicia (Título V TFUE, arts. 67 a 89) no sólo autoriza sino exige al Parlamento Europeo legislar en desarrollo de los derechos de la CFDUE, así como en la materia penal y en la cooperación judicial penal, para combatir más eficazmente los delitos especialmente graves y de ámbito transnacional, reforzando la protección de la víctima ante el proceso penal, y estableciendo para ello un nuevo espacio penal europeo, con normas penales mínimas y sanciones vinculantes para los EE.MM ${ }^{15}$.

Como resulta entendible, el PE ha debatido incesantemente, y con sobrados motivos, la crisis financiera y sus dimensiones atinentes a la gobernanza económica. Pero ello no le resta ningún ápice de urgencia a la necesidad de preservar las reglas garantía de los derechos en la UE (art. 2 TUE) ${ }^{16}$.

Desde esta perspectiva, la crisis que impacta sobre los valores fundacionales de la Unión Europea no es menos importante ni urgente que la del euro - a mi juicio, lo es más-. Por lo que los denominados «criterios de Copenhague», que se exigen a los candidatos a la adhesión, deben comenzar a exigirse también, con todos los rigores marcados en los aspectos «fiscales» (recortes presupuestarios), una vez dentro del $c l u b$ y a todo lo largo del trecho de pertenencia al mismo (art. 2, 3 y 4 TUE).

Ejemplo de este estado de cosas es, tal como hemos visto antes, el que nos brinda Hungría, donde el partido en el Gobierno -Fidesz, del PP europeoconsumó en 2012 la aprobación de la llamada «cuarta enmienda» a la Constitución de 1949 (después de las adoptadas en 1989,1990 y las impulsadas en 2010, tras su llegada al Gobierno $)^{17}$. En ella se desautoriza al Tribunal Constitucional, al restablecer todos y cada uno de los contenidos de una propuesta de reforma anterior que habían sido declarados no conformes con la Ley Fundamental por una sentencia dictada en diciembre por el propio Alto Tribunal, desoyendo abiertamente la regla de que en democracia se puede tener o no un Tribunal Constitu-

y FUE). Para un comentario doctrinal, cfr. Fernandez Rozas, José Carlos: «La compleja adhesión de la UE al Convenio Europeo de Derechos Humanos y las secuelas del Dictamen 2/2013 del Tribunal de Justicia», La Ley Unión Europea, n. ${ }^{\circ} 23$, Febrero 2014, pp. 40-56; y LlOPIS NADAL, Patricia: «La necesidad procesal de la adhesión de la Unión Europea al CEDH: Un asunto que continúa pendiente tras el dictamen 2/13 del TJUE», Revista Electrónica de Estudios Internacionales, n. ${ }^{\circ}$ 29, Junio 2015.

15 Cfr. sobre este objeto, Lopez Aguilar, J F.: «El Parlamento Europeo, legislador del Espacio de Justicia penal de la UE», Revista de Derecho Político, n. ${ }^{\circ}$ 93, 2015.

16 Véase LABAYLE, Henri: Towards the Negotiation and Adoption of the Stockholm Programme's Successor for the Period 2015-2019, European Parliament, 2013.

17 Cuarta Enmienda de la Ley Fundamental, presentada el 8 de febrero de 2013 en forma de proyecto de ley presentado por un diputado a título individual y aprobada por la Asamblea Nacional húngara el 11 de marzo de 2013, que, entre otras disposiciones, integra en el texto de la Ley Fundamental las Disposiciones Transitorias (con algunas excepciones, incluida la disposición que exige el registro de los votantes), anuladas por el Tribunal Constitucional de Hungría el 28 de diciembre de 2012 por razones de procedimiento (sentencia n. ${ }^{\circ}$ 45/2012), así como las disposiciones restantes de dicho documento que son de carácter realmente transitorio. 
cional, pero cuando se le tiene, hay que respetar lo que dicta y cumplir con sus sentencias.

Pero es que, además, esa enmienda a la Constitución húngara de 1949 ha impuesto igualmente condiciones al pluralismo religioso y al pluralismo informativo, crecientemente intervenido por el gubernamentalismo de los medios de comunicación públicos y privados. Y restablece el mecanismo de asignación jurisdiccional individualizada de casos por la llamada Oficina judicial, un resorte de poder que había suscitado protestas en el $\mathrm{PE}$, sin que se den garantías explícitas del respeto al «proceso debido»y al «juez imparcial» predeterminado por la ley. Al actuar así, es notorio que el Gobierno de Orban y la abrumadora mayoría conservadora en el Parlamento húngaro desoyeron al mismo tiempo al Consejo de Europa, al Secretario General del Consejo de Europa, a la Comisión de Venecia y al Presidente del $\mathrm{PE}^{18}$.

Durante la pasada Legislatura europea 2009-2014 lideré la referida delegación en Budapest de la Comisión de LIBE, que tuve el honor de presidir durante esos 5 años. Tuve entonces ocasión de subrayar, en mis intervenciones y durante la rueda de prensa con que concluyó la misión, que el PE no es ningún «intruso» ni una «intromisión»en Hungría, no ejerce ninguna «injerencia»; no es una «potencia extranjera»: representa, mediante su elección democrática directa, a 500 millones de ciudadanos europeos, entre los que se cuentan los más de 10 millones de húngaros. Por mandato del PE, la Comisión que presidí entonces deliberó y adoptó el referido informe sobre la situación de los derechos y la democracia en Hungría. Y el PE debe, a mi juicio, seguir esforzándose actualmente y en el futuro mediato para que en toda la crisis - no sólo «pese a la crisis» sino especialmente en la crisis_-, se siga cumpliendo a rajatabla con la primera regla de la pertenencia a la UE: la sujeción voluntaria al imperio de la ley, a la primacía del Derecho y a los valores fundantes de la construcción europea (art.2 a 6 TUE).

\section{La extrema derecha europea: otra serpiente en el huevo}

Con todo, lo cierto es que Hungría, Estado miembro de la UE desde la «gran ampliación» de 2004, expresa una malaise europea. Hemos reseñado ya hasta qué punto el Gobierno de Viktor Orban ha alimentado a este respecto una retórica

18 Véase la declaración conjunta de 11 de marzo de 2013 del presidente Barroso y del secretario general Thorbjorn Jagland, en la que reiteran su preocupación en relación con la Cuarta Enmienda de la Ley Fundamental de Hungría en cuanto al principio del Estado de Derecho; las declaraciones del Consejo y la Comisión sobre la situación constitucional en Hungría en el debate celebrado en el Pleno del Parlamento Europeo el 17 de abril de 2013; el dictamen de la Comisión de DDHH (2011)10 de 25 de febrero de 2011 del Comisario de Derechos Humanos sobre la legislación relativa a los medios de comunicación a la luz de las normas del Consejo de Europa sobre la libertad de los medios de comunicación; y las declaraciones de la OIDDH de 15 de marzo de 2013 expresando su preocupación por la aprobación de la Cuarta Enmienda de la Ley Fundamental. 
nacionalista crecientemente antieuropea, rayando, de modo cada vez más expreso, la rabia antieuropea o eurofobia. Su más reciente movimiento a propósito del pánico desatado por la mal llamada «crisis de refugiados» ha sido asimismo sintomático: frente y contra las fronteras de sus países vecinos, EE.MM. de la UE, el Gobierno de Hungría ha «levantado muros» y restablecido barreras y controles. Se ha negado a aceptar «refugiados» ante toda decisión adoptada en el Consejo para el establecimiento de «cuotas» eventualmente «vinculantes» de «corresponsabilidad» (la llamada burden sharing) en la gestión de los llamados «esquemas de realojamiento» (relocation) de demandantes de asilo... y ha llegado a amenazar con la convocatoria de un referéndum que respalde la negativa de Hungría a aceptar refugiados (cerrando para ello fronteras con Austria, Rumanía, Eslovenia.... $)^{19}$.

Este es, por tanto, un debate que afecta no solo a Hungría y sus países vecinos. Alcanza a toda Europa y la afecta por entero, en la peor crisis de su historia. Desafía los llamados «criterios de Copenhague» (requisitos de adhesión a la UE adoptados en 1993: reglas de Estado de Derecho, democracia representativa, derechos fundamentales, separación de poderes, tutela judicial y protección de minorías, además de acreditar capacidad para asumir las reglas del mercado interior). Criterios que, insisto de nuevo, no solamente han de exigirse cuando se ingresa en el club, sino a todo lo largo de la permanencia en el Club de socios de la integración europea ${ }^{20}$.

La Comisión Europea — «guardiana de los Tratados», en la descripción más clásica de su papel definitorio — es, y debería seguir siendo, la institución encargada defender los valores europeos puestos actualmente en crisis, más gravemente que nunca, de la mano del Gobierno de Viktor Orban en Hungría y de cuantos le acompañen en sus dinámicas regresivas de retroceso en derechos, libertades, pluralismo y sujeción a la regla del «imperio de la Ley». Es tarea de la Comisión — «guardiana de los tratados»— recordar a este Gobierno húngaro o a cualquier otro — por si aún no se ha enterado- que incorporarse a la UE significa formar parte de un espacio — no ya un «club» de derechos y obligaciones vinculantes para todos aquellos EE.MM que voluntaria y solemnemente han expresado su consentimiento y su voluntad de cumplir los protocolos de adhesión. Y particularmente un «espacio libre de pena de muerte» y de cualquier forma de debate sobre su reinstauración.

Dicho más claramente, cualquiera que introduzca ese asunto en el debate político, como ha llegado a hacer recientemente Viktor Orban, debería tener que responder ante toda la UE como genuina Unión política. Porque cuestiona una conquista de la civilización del Derecho y de las libertades que debe ser preserva-

19 Véanse los informes Fundamental rights at land borders: findings from selected EU border crossing points, Agencia de los Derechos Fundamentales, 2014 y 2015.

20 Véase Carrera, S, Guild, E., Hernanz, N: The Triangular Relationship between Fundamental Rights, Democracy and Rule of Law in the EU — Towards an EU Copenhagen Mechanism, European Parliament, 2013. 
da activamente por la guardiana de los Tratados, que eso es justamente la Comisión. Por eso mismo debatimos estos asuntos en el PE. Cuando un gobernante de la UE se atreve a hablar — como lo ha hecho Orban ante el Europarlamento- de sus lucubraciones acerca de la potencial «reinstauración de la pena de muerte» como un objeto hipotético del que se pueda discutir bajo la «libertad de expresión», está lisa y llanamente faltándole al debido respeto al contrato que adquirió cuando pasó a formar parte de la UE. De análogo modo, debería responder de las consecuencias sistémicas sobre el conjunto de la UE de la secuencia descrita, por la que, apoyándose exclusivamente en su mayoría parlamentaria, el mismo Gobierno de Orban acometió y resolvió, como hemos visto anteriormente, la cuarta reforma de la Constitución húngara — que entró en vigor en el año 2012—, imponiendo un severo retroceso democrático a los estándares comunes que distinguen a la UE y a sus EE.MM. Y al mismo tiempo implementaba - como continúa haciendo- , políticas restrictivas en asuntos que revisten enorme sensibilidad - la criminalización de los «sin techo», por señalar solo un ejemplopor más que contraríen los valores de la UE, menoscabando derechos y libertades que son parte del acervo comunitario europeo.

En paralelo a estos sucesos, en las elecciones generales celebradas en Finlandia en 2011 el partido Finlandeses Auténticos, dirigido por Timo Soini, consiguió un resultado preocupante en Finlandia, deviniendo tercera formación del país, con un discurso ultranacionalista y profundamente antieuropeo...en Finlandia, nada menos. Y el UKIP de Nigel Farage fue la fuerza más votada en el Reino Unido en las últimas elecciones europeas, de 2014, erigiéndose en una fuerza decisiva ante el referéndum del Brexit del 23 de junio de 2016, capitalizando de inmediato su resultado como el júbilo de un «Independence Day» (!!!)...en Reino Unido, nada menos...

El 6 de diciembre de 2015, el Front National (FN) formación ultraderechista liderada por la eurodiputada Marine Le Pen, dio prueba de su pujanza en una sociedad acuciada por la zarpa del terror que la golpeó el 13 de noviembre. Fue la fuerza más votada en las elecciones regionales de 2015, con un 29,1\% de los votos, por delante de la derecha PPE de Sarkozy, (26,78\%) y del PSF de François Hollande $(22,99 \%)$, quien, pese a su efectista respuesta tras los terroríficos atentados en París - con el constante uso de símbolos del Estado, la Marsellesa y la bandera tricolor- - no ha podido todavía desactivar el discurso del odio y la islamofobia esgrimido por Le Pen u su formación extremistas... Todo eso en Francia, nada menos.

La ultraderecha y sus huestes refuerzan el componente identitario más primario en las estructuras sociales de los EE.MM, situándose constantemente en una posición de confrontación cultural frente a la extranjería, pese a la inmigración y, muy particularmente, frente a la comunidad musulmana (por más que integrada en Francia por ciudadanos/as nacidos en la República francesa, por lo que son franceses/as de pleno derecho), estigmatizada de un modo cada vez más desinhibido como una amenaza para la «Francia para los franceses» preconizada por el FN. 
También por este contexto, que atraviesa las fronteras europeas al tiempo que las restablece, las acciones llevadas a cabo por Orban en Hungría —el ejemplo más notorio- exigen una acción europea del PE y de la Comisión Europea. Y aún así, ello obstante, la Comisión se ha mostrado hasta el momento renuente a la hora de poner en marcha el llamado «mecanismo del Estado de Derecho» para evaluar el deterioro de la calidad democrática, del respeto de los derechos de las minorías, de la independencia judicial y del derecho al juez predeterminado por la ley que se han consumado en Hungría de la mano de la reforma constitucional con los votos de Fidesz.

Así, clamorosamente lo pone de manifiesto nada más y nada menos que la presentación de una iniciativa ciudadana europea registrada con sus firmas —al menos un millón recaudadas en ocho EE.MM (un cuarto del total de la UE) el pasado 30 de noviembre de 2015 ante la Comisión para exigir la aplicación del artículo 7 del TUE: el dispositivo que prevé que, por mayoría cualificada, el PE solicite al Consejo que considere la retirada de sus derechos de voto a cualquier Estado miembro donde se haya constatado una «quiebra grave y sostenida de los principios fundamentales» de la construcción europea.

\section{Democracia vs. populismo (El precedente italiano ¿patología o premonición?)}

¿Fue Berlusconi pionero del populismo europeo? Formulemos la pregunta en otros términos ¿Fue su Gobierno en Italia una anomalía, un eslabón enfermo en la cadena de las democracias europeas surgidas después de la II Guerra Mundial? ¿O fue más bien un precursor del horizonte anticipatorio al que se avecinan todas?

Desde los años 70 del pasado siglo, la democracia italiana, fundada sobre la Constitución de 1948 (30 años anterior a la española), con sus sucesivas reformas, ha sido persistentemente objeto de un debate intelectual e ideológico cargado, de alto voltaje, y perdurable a lo largo de las décadas. Y particularmente intenso ha sido el debate doctrinal suscitado en Italia — constitucionalistas, politólogos, sociólogos, comparatistas- a lo largo de los años 80 y 90 del pasado siglo: su argumento principal es el que confronta a quienes han visto en los síntomas de la desafección cronificada de la sociedad italiana hacia sus instituciones — con altos niveles de «cinismo político» y desconfianza ante las muestras de corrupción pandémica y de colusión de intereses entre poderes públicos, negocios ilícitos y crimen organizado (criminalità di stampo mafioso) — una excepción o contraejemplo de las debilidades y amenazas que gravitan sobre otras democracias avanzadas, frente a quienes entrevén, más bien, en la «italianización de la democracia europea» el síndrome degenerativo de una representación política cada vez más desvinculada de la ciudadanía, no solamente en Italia sino extensiva a toda Europa.

No en vano, el estigmatizador vituperio de la «casta» —entendiendo por miembro de la misma a todo el que se dedique a la política en las instituciones- 
y los pioneros ejercicios de populismo mediático — desde Berlusconi a Beppe Grillo- arrastra un distintivo marchamo italiano en su origen ${ }^{21}$. Lo mismo que sucedió con el originario fascismo mussoliniano: porque éste fue, no lo olvidemos, un movimiento reaccionario de confrontación exasperada contra el liberalismo (bajo la acusación de régimen «decadente») y contra los riesgos que para las burguesías y aristocracias nacionalistas planteaba en el primer tercio del siglo $\mathrm{xx}$ la insurgencia de la clase obrera y de los partidos de izquierda surgidos para hacer valer los derechos de los trabajadores. Y no fue sólo en Italia, sino en todo el continente europeo.

El electorado dispuesto a sostener ese tipo de discursos y propuestas en la frontera del $25 \%$ o del $30 \%$ de los votos conmociona y desafía la razón crítica de muchos. Pone de manifiesto un sector significativo del cuerpo electoral que en Italia - lo mismo que en otras latitudes, así por ejemplo en España-, se muestra indolente o incluso inmune a la corrupción ostensible de gobernantes electos. Así, una parte significativa de la sociedad italiana se ha demostrado capaz de apoyar con su voto las histriónicas puestas en escena de Berlusconi a pesar del desastroso balance social de su historial — tres veces primer ministro-, y sobre todo, a pesar de la acumulación de procesos penales por todo tipo de delitos económicos e indicios de asociación mafiosa, por no hablar de los episodios relacionados con su conducta personal.

Por su lado, el Movimiento Cinque Stelle encabezado por Beppe Grillo, incorpora un virulento ejercicio de contraprogramación populista: reverso del de Berlusconi. El grito y el aspaviento sustituyen al razonamiento, sin darle una sola oportunidad a la contraposición racional de respuestas a la crisis para pasar directamente al «ique se vayan todos!». Frente a la tentación de la simplificación, no solamente en Italia sino en una buena parte de los EE.MM de la UE, resulta cada vez más costoso afirmar contracorriente que no siempre es practicable una cosa y su contraria: muchos manifestantes que braman su protesta contra la desconexión de los representados frente a sus representantes exigen un cambio profundo de la forma de hacer política y mayor proximidad de su representación mientras premian lo contrario, castigando con el voto a quienes se toman el esfuerzo de intentar síntesis racionales de la complejidad, dificultad y riesgos que comporta tal esfuerzo de rectificación.

La «nueva comunicación» mediante las redes sociales difícilmente convalida el discurso antipolítico ni la contradicción de exigir «proximidad» a la política al mismo tiempo que se insulta a quien se preste a escuchar o a compartir cualesquiera sentimientos de agravio o indignación. La saturación de soflamas regeneracionistas, no pocas veces invocando la inminencia de los «cirujanos de hierro»

21 Para una genealogía de la pujante puesta en circulación del constructo de la «casta» como herramienta en el combate por su deslegitimación de la democracia representativa, al margen de su antecedente remoto en los precursores prefascistas de la teoría de las élites que fueron Gaetano Mosca y Wilfredo Pareto, su punto de partida reciente puede trazarse en el libelo periodístico «La casta», de S Pizzo y G Astella. 
que en lea España de fines del siglo XIX preconizó Joaquín Costa, nunca funcionó en la historia como tratamiento de choque de higiene democratizadora. Más bien todo lo contrario: esa «regeneración» fue a menudo la antesala de utopías regresivas y fracturación social. El riesgo inminente es el «desarme» de la democracia hasta dejarla inerme frente a la tentación de propugnar a gritos una «democracia real» cada vez más despectiva con demócratas de carne y hueso —-más escasos de lo que se cree-, y en la que los razonamientos se vean cada vez más asfixiados.

\section{Otros casos: España (y sigue...)}

De modo que ahí lo tenemos: a lo largo de toda la crisis que arrancó en 2008 - y bajo el paraguas de la misma - hemos asistido a un pavoroso retroceso en materia de derechos sociales y libertades impuesto por numerosos gobiernos de diferente signo a todo lo ancho de Europa. A rebufo de esta crisis, y con el pretexto de la crisis, se ha venido atornillando sistemáticamente una involución cada vez más agresiva contra la nuestros propios estándares de calidad democrática, de pluralismo informativo, y de la responsabilidad y la dación de cuentas de los gobernantes en la mejor garantía de los derechos de los ciudadanos ${ }^{22}$.

Ya en el año 2013, un informe elaborado por el prestigioso Think Tank Demos (equipo británico de estudios políticos y sociales) puso de manifiesto, con profusión de datos empíricos contrastados, hasta qué punto ha pasado el tiempo en que la «democracia se daba por sentada» en Europa: "Democracy can no longer be taken for granted!» ${ }^{23}$. En efecto, la acumulación saturada de recortes y contrarreformas delinean a estas alturas un paisaje de backsliding (deterioros/retrocesos) de las libertades civiles... Y me reafirmo: no hablamos sólo de Hungría, ni de Rumanía o Bulgaria... como podrían suponer alguna lectura reductiva de lo que está pasando; pongamos que estamos hablando de lo ocurrido en Reino Unido; de lo que ha ocurrido en Italia... o en España, en estos últimos años ${ }^{24}$.

Baste aquí ejemplificarlo en el debate suscitado en España por la Ley Orgánica de Seguridad Ciudadana ${ }^{25}$, que transpone al plano de los «derechos civiles» (derechos y libertades) retrocesos anteriormente consumados contra los derechos sociales y de los trabajadores. La Ley — periodísticamente conocida como «Ley mordaza»— propone sancionar con multas cuantiosas comportamientos que no

22 Véase, al respect, Ivanković-Tamamović, A: The Impact of the Crisis on Fundamental Rights across Member States of the EU - Comparative Analysis, European Parliament, 2015.

23 Véase el extenso examen en Birdwell, J, Feve, S, Thryhorn, C y V, Natalia: Backsliders: Measuring Democracy in the EU, Demos, 2013.

24 Véase el interesante y documentado análisis elaborado por encargo de la Comisión LIBE por las profs. Lladós Vila, J y Freixes, T: The Impact of the Crisis on Fundamental Rights across Member States of the EU - Country Report on Spain, European Parliament, 2015.

25 Ley Orgánica 4/2015, de 30 de marzo, de protección de la seguridad ciudadana. 
solo nuestro Código Penal no tipifica - y que los jueces, por lo tanto, nunca han considerado delito- sino que en puridad constituyen un ejercicio de derechos constitucionalmente garantizados: las libertades de expresión, (que incluye la de la crítica) y de reunión y de manifestación de que disfrutan todos los ciudadanos españoles. Se ejerce así una vuelta de tuerca al clima desalentador de ciertas expresiones de crítica. El ánimo disuasorio pretende restringir las concreciones legítimas de disenso, protesta u oposición «en la calle» o en «las redes», acaso acallando incluso parte de ese malestar que se ha venido incubando a causa de la exasperación de las desigualdades, y consiguientes injusticias, en el reparto de sacrificios derivados de la crisis, así como del «adelgazamiento» o desmantelamiento de servicios públicos que venían dando cobertura a derechos que habían sido asumidos por la ciudadanía por su universalidad.

No se trata, como a menudo se alega, de sancionar «desórdenes públicos», sino de la revisión general del Estado social cuyos derechos prestacionales (educación, sanidad, servicios sociales) se ha confiado en España, de acuerdo con nuestra arquitectura territorial de competencias en el Estado Autonómico, a las CCAA. Se llega así a alcanzar también el propio Título I de la Constitución (derechos fundamentales y libertades públicas). Numerosos analistas han advertido en esta secuencia una pérdida alarmante de densidad normativa en una Constitución a la que sin embargo continúan denegándose las requeridas (y siempre aplazadas) reformas, sin acometerlas ni tan siquiera en aquellos puntos que más consenso suscitan.

La reseñada Ley de Seguridad Ciudadana interactúa con lo que queda de la llamada «Ley de Tasas» que introdujo, desde el inicio de la legislatura 20112015, barreras económicas contra el acceso a la Justicia singularmente gravosas para los menos pudientes, tanto más en la Jurisdicción contencioso-administrativa para poder recurrir las multas económicas impuestas desde la administración y el poder ejecutivo ${ }^{26}$.

Y todo esto, en España, no en Hungría ni en Rumanía... Durante los últimos años, el Comisario Europeo de Derechos Humanos del Consejo de Europa, de nuevo el letón Nils Muižnieks, se ha mostrado reiteradamente preocupado por estos retrocesos de las libertades en España. Los condicionamientos impuestos a la desigualdad en leyes educativas, civiles y penales y por el retorno a una vieja retórica contra la inmigración...

Con especial intensidad, esa preocupación de escala paneuropea se desató durante el tiempo de las manifestaciones convocadas en su día por el movimiento $15-\mathrm{M}$ y sus sucesivas secuelas. Aquellas imágenes, es cierto, consiguieron romper los telediarios de medio mundo. La convocatoria orientada a «rodear el Congre-

26 Ley 10/2012 de 20 de noviembre, por la que se regulan determinadas tasas en el ámbito de la Administración de Justicia y del Instituto Nacional de Toxicología y Ciencias, modificada en dos ocasiones; la primera, por el Real Decreto-ley 3/2013, de 22 de febrero y, la segunda, por el Real Decreto-ley 1/2015, de 27 de febrero. 
so» reveló gráficamente la gravedad de la situación y la contundencia del mensaje: la estampa de España en la prensa extranjera aparecía sumida en un estado de ánimo, valga la expresión, preinsurrecional. La magnitud de las protestas contra los deterioros irrogados en el siempre limitado crédito democrático traducía la exasperación de millones de españoles ante la palmaria injusticia en el reparto de los sacrificios impuestos por el abyecto manejo de la crisis que se ha venido imponiendo sin miramientos en los costes. La percepción extendida en la contestación social era, y continúa siendo, la de que la política hasta la fecha aplicada, además de injusta, simplemente no funciona: la dieta de austeridad recesiva ni ha acabado con la crisis, ni ha mejorado tampoco malheridas variables macroeconómicas que describen el mal estado del paciente. En el sustrato de muchas protestas subyacía la convicción de que, desde una concepción supuestamente tecnocrática, se imponían recortes draconianos y «ajustes» crudamente darwinistas... sin pestañear siquiera ante el sufrimiento social que cada medida generase, ni contemplación alguna ante los cientos de miles de puestos de trabajo que cada vuelta de tuerca acabara destruyendo sin margen para discutir opciones alternativas ni para el remordimiento.

Parece incontestable, pues, que la sensación de injusticia desatada por la gestión de la crisis por los gobiernos europeos ante el dolor y la desesperanza que sus opciones ideológicas han desencadenado ha acabado derivando en una redefinición de los paisajes políticos europeos y nacionales en los EE.MM.

De modo que, desde el arranque de la crisis, la literatura politológica ha abundado en el esfuerzo de interpretar correctamente la llamada 'antipolítica'. Se trata de una deriva que apunta el enfrentamiento de la «ira de la multitud» (la «contestación en la calle») con los Parlamentos representativos del pluralismo político. Un pluralismo político que, como tal, ni se representa ni se encierra en el interior de un todo homogéneo o indistinto, sino que expresa y vertebra a sociedades abiertas en que laten opciones y alternativas enfrentadas y en conflicto e indignación ante el balance de desigualdades crecientes y ante los signos de ruptura de la solidaridad intergeneracional y del pacto de rentas que debería dar lugar a una redistribución equitativa de cargas.

Como constitucionalista y como europeísta comprometido con valores, me sumo desde hace años a quienes vienen urgiendo un debate riguroso desde la Constitución española de 1978 que abra paso a su reforma: sistema electoral, parlamentario y autonómico, tantas veces postergado con el argumento manido de que «no es el momento» y de que «no hay consenso» (como si los «consensos» precedieran al debate...) aun a riesgo de que cuando «llegue el momento» sea ya demasiado tarde para rescatar del naufragio ningún resto de la transición. Con la misma convicción con que combato en el PE, durante los últimos años, esta gestión de la crisis que la ha hecho interminable e inaceptablemente injusta, propugno un reseteo de la democracia constitucional en España.

Son, en efecto, cada vez más numerosos los especialistas que ven la necesidad, y sus dificultades, de nadar a contracorriente, con fuerte marejada en contra, y 
aspirar a reformar con cierta profundidad - y, por supuesto, rigor - una Constitución que ya no es «joven» desde el respeto a las reglas previstas para ese objetivo, vista la preponderancia de la desafección y tensión nacionalista. Esas coordenadas se arriesgan a la confusión, en España como en todas partes, del aliento de lo que se autorrepresenta como marea constituyente con el vendaval destructivo de la demagogia y de la antipolítica. Aun así, es improrrogable, a mi juicio, aprestarse a discutir, sin tabúes ni concesiones al pánico, una revisión constitucional marcada por la estatura de la gravedad del envite. Pero ese objetivo histórico no es compatible, sin más, con «que se vayan todos» (al modo del exabrupto que popularizó Cinque Stelle). Como si esos «todos» fueran «todos iguales» o incluso «el único problema». Como si los políticos fueran el «único problema»y «acabar con la política» fuera una solución. Seguramente otra política, otra forma de hacerla y desde luego otra Europa, serían parte de los términos de una ecuación que no se despejará ni a gritos ni difamando en la red con ese discurso del odio y esa política del odio que tiene curso sin freno en el anonimato de Internet. Retomar la discusión sobre la Constitución, con una revisión a fondo que restituya dignidad a una democracia herida, cambiando la orientación de la construcción europea. Y en anteriores escritos abogo desde hace tiempo por reparar los descosidos en nuestra arquitectura constitucional, cuyo desgaste de materiales rechina ya en muchas costuras ${ }^{27}$.

$Y$ es verdad que, al respecto, algunos tratadistas aluden a la oportunidad de hacer de las Cortes que acometan ese empeño unas constituyentes, mientras que otros subrayan que de ningún modo ha de apuntarse a una nueva operación constituyente sino tan solo de reformar la Constitución vigente, la de 1978, con vistas a relanzar su hoy desgastada capacidad de integración y de marco democrático para el pluralismo político y para la articulación de opciones alternativas. Se trataría, en buena medida, de un falso debate sobre el que la teoría constitucional arroja desde hace mucho lecciones clarificadoras.

Así, en España, aquí y ahora, parece, a juicio de muchos, llegado de una vez el momento de acometer la puesta en hora del texto constitucional superando de una vez la fase «procedimental»y «transitoria» del Título VIII que abre paso a la «organización territorial del Estado», y certificando un acta de maduración potencialmente federal de nuestra integración unitaria de la diversidad y el reconocimiento de los hechos singulares, de la diferencialidad de la propia identidad y vocación de autogobierno (lenguas, culturas, foralidad, derechos propios, regímenes fiscales propios, e insularidad...). Pero también, y no menos, superando de una vez esa atormentada historia que Benito Pérez Galdós historió magistralmente en sus Episodios Nacionales: esa España en la que las Constituciones nunca se sucedieron unas a otras de acuerdo con las reglas previstas para su propia refor-

27 Vid., Lopez Aguilar, J F: «Reformar la Constitución, ahora. Antes de que sea ya tarde», El Cronista del Estado Social y Democrático de Derecho, n. ${ }^{\circ}$ 53-54, 2015, pp. 28-33. 
ma, sino a través de turbulencias o disrupciones abruptas. Rupturas que no reformas: cuartelazos, asonadas, pronunciamientos, golpes de Estado, fusilamientos masivos y guerras civiles, fueron invariablemente preludio de cada nuevo régimen. De modo que, como vengo sosteniendo en anteriores escritos, es hora de que la Constitución de 1978 madure su propia reforma de acuerdo con sus propias reglas.

\section{EL CASO DE POLONIA Y SUS SECUELAS EN LA UE: EL SINDROME DE PUTINIZACIÓN.}

\section{Breve noticia histórico-constitucional de Polonia: encuadre de la reforma de la Justicia Constitucional}

Visto todo lo anterior, procede examinar con detalle el caso de Polonia en la $U E$ y su encuadre en el llamado «dilema de Copenhague».

En la perspectiva de lo que en su momento representó la «Gran ampliación de la UE»(diez nuevos EE.MM. en 2004), Polonia no fue, en ningún momento y de ningún modo, un caso de «país menor». Tampoco, consiguientemente, un desafío menor para el conjunto de la UE. Sus más de 40 millones de habitantes (una población que se aproximaba a la española a principios del siglo XXI), y su extenso territorio, hacían de Polonia el país de mayor peso entre los candidatos provenientes de la esfera de antigua influencia soviética ${ }^{28}$.

Polonia añadía además otras características de singular interés y potencial complejidad. Para empezar es el único país de todo el continente europeo que ha mudado por completo de países fronterizos: ha desaparecido la extinta URSS (ahora es frontera con las bálticas Letonia, Bielorrusia, Ucrania... y Rusia en Kaliningrado); la extinta RDA (ahora lo es Alemania) y la extinta Checoslovaquia (ahora son dos Repúblicas, ambas EE.MM. de la UE). Además, es un país cuya transición política (de la dictadura comunista a la democracia representativa), y cuya evolución social (la nueva estructura económica que ha transformado un país agrario en un país inserto en la economía de servicios y de mercado) ha sido seguida con particular atención por los analistas y por la opinión pública (especialmente en la fase de desmantelamiento del régimen férreamente controlado por el Partido Comunista) con el protagonismo del Solidarność y su líder Lech Wałęsa, luego Presidente de Polonia.

Sirva este recordatorio para encuadrar brevemente la historia constitucional polaca. Sobresale el dato de que Polonia incorporó la primera Constitución escrita de la historia del constitucionalismo europeo, de 1791 (cuatro meses anterior a la

28 Sigo, en este apartado, la síntesis elaborada por VALvidares SuAREz, M., «El Constitucionalismo polaco: pasado y presente», REDC, n. ${ }^{\circ}$ 65, 2002. 
de la Revolución Francesa). De la fugaz vigencia de una Constitución se abrió paso a la de Constitución de 1921, por el que se establece la separación de poderes, con un legislativo bicameral (Sejm o Asamblea Nacional y Senado), un ejecutivo (con un Presidente de la República de elección parlamentaria y un Consejo de Ministros) y un Poder Judicial revestido de esenciales garantías de independencia.

La inestabilidad política y territorial de Polonia hubo de padecer la dictadura de Piłsudski (1926), la invasión nazi (1939) y la II Guerra Mundial (19391945). Una breve y provisional Constitución socialista dio lugar a la de 1952, de clara impronta soviética. La tradicional separación de poderes dio paso a la concentración de poderes, en un Consejo de Estado, característico del centralismo soviético.

La proliferación de protestas (malestar estudiantil y obrero, aglutinado a menudo por el clero católico) explica, a fines de los años 70 y principios de los 80 , el liderazgo social del Solidarność de Wałęsa. La llamadas «negociaciones de la mesa redonda» de 1989 condujeron a una serie de leyes constitucionales ( 7 de abril y 29 de diciembre de 1989, 9 de marzo de 1990 y 19 de abril de 1991), por las que se resucita el Senado y la jefatura de Estado (presidente elegido por el Sejm y, desde 1990, por sufragio universal).

De esa situación se transita a la que es hoy conocida como «Pequeña Constitución» de transición (la Ley Constitucional del 17 de octubre de 1992), que derogó la de 1952 y recupera la arquitectura de la separación de poderes, el parlamentarismo bicameral, el ejecutivo bicéfalo (Presidente y Consejo de Ministros con Primer ministro al frente) y la prefiguración de un Estado democrático de Derecho.

La Ley Constitucional de 1992 regula novedosamente la elección popular (por sufragio universal) del Presidente de la República y la investidura (y censura) del Primer ministro bajo los parámetros del «parlamentarismo racionalizado», en un mecanismo revestido de notable sofisticación (con sucesivas votaciones), estableciendo incluso un llamativo dispositivo de "presunción de confianza provisional» revalidable en seis meses en caso de agotarse las votaciones sin haberse superado el umbral de investidura.

A partir de estos antecedentes, la historia constitucional polaca conduce a la Constitución de 1997 — derogatoria de la de 1992 — que no solamente perfila y perfecciona la apuesta por un «Estado social y democrático de Derecho» en la República Polaca sino que establece un catálogo amplio de derechos constitucionales (civiles, políticos, económicos y sociales), además de conjugar la organización unitaria del Estado con la autonomía local de los poderes locales.

Pues bien, vistos los antecedentes, la actual configuración constitucional, y sus correlativos proyectos de desarrollo legal, tiene como cometido redefinir la construcción de fuerzas internas en el propio Sejm (Asamblea Nacional) asegurando una mayoría ultraconservadora en sintonía con la lectura que el PiS promueve y preconiza acerca de los mandatos de gobierno y legislativo que se desprenden de las elecciones de diciembre de 2015. 
El punto más relevante, en lo que nos interesa, se refiere a la inserción de un Tribunal Constitucional (TC) con funciones de jurisdicción constitucional concentrada y diferenciada del Poder Judicial, cuyo estatuto profesional (independencia, inamovilidad, incompatibilidades) queda definido igualmente en la propia Constitución.

La Constitución Polaca de 1997 establece, efectivamente, un TC (arts.188197) con una configuración análoga a la prevalente en el Derecho comparado continental europeo.

Por su parte, el temprano desarrollo legislativo de esta institución capital es el que queda fijado por la Ley del 1 de agosto de 1997. Se perfila en ella un órgano de jurisdicción constitucional concentrado, combinando el control abstracto (recurso) y el concreto (cuestión) de constitucionalidad de las leyes, junto a la garantía de derechos (recurso de amparo) conflicto constitucionales y control sobre la constitucionalidad de los partidos políticos (art. 188.4).

Complementariamente, la supremacía normativa de la Constitución Polaca queda garantizada en su Capítulo XII (Reforma Constitucional, arts. 228 y ss). Se excluye de la iniciativa tanto al Gobierno como a la iniciativa popular, exigiéndose para su aprobación una mayoría cualificada y referéndum vinculante en caso de afectar al segmento más blindado del texto constitucional (principios fundamentales, reforma constitucional). No hay límite material a la eventual reforma de la Constitución, pero sí queda establecida la prohibición de acometerla durante la vigencia de alguno de los estados de crisis previstos en la propia norma (una previsión que resuena claramente a la contemplada en el art.169 de la Constitución española de 1978).

Pues bien, a partir de estos mimbres, la Constitución Polaca de 1997 ha sido modificada en dos ocasiones relevantes hasta la fecha. El 8 de septiembre de 2006 se modificó el art. 55 para prohibir la extradición de ciudadanos polacos (salvo delito de genocidio o crímenes contra la humanidad cubierto por un tratado internacional ratificado por Polonia). El 7 de mayo de 2009 se reforma el art. 99 relativo a la mayoría de edad para el sufragio pasivo a la Sejm (21 años) y al Senado (30 años), y prohíbe la elegibilidad de personas sentenciadas a prisión por delitos dolosos.

Ahora, visto lo visto ¿de qué hablamos cuando hablamos de un caso de «regresión constitucional» en Polonia digno de atención europea?

La alarma sobre el caso polaco se ha desatado, en efecto, a todo lo ancho y largo de la UE durante el último año. Ya hemos reseñado aquí cómo el antecedente húngaro, con la restricción a los derechos de las ONGs y de las minorías, los ataques acumulados contra la independencia del Poder Judicial y los retrocesos en libertades y pluralismo político (singularmente en los estándares de pluralismo informativo con el control gubernamental de los medios de comunicación) desataron ya la alarma y la preocupación de las instituciones europeas acerca de la potencial certificación de una violación «grave y sistemática» del «Estado de Derecho» (Rule of Law) tal y como prevé el art. 7 TUE. Y cómo, a partir de ahí, 
hemos sido numerosas las voces que en el PE hemos urgido la actuación de las llamadas «Rule of Law Warning» $\mathrm{y}$ «Rule of Law Mechanism» eventualmente conducente a la activación del dispositivo contemplado en el art. 7.

Pues bien, la secuencia en Polonia — y de lo que ha dado en llamarse el caso de Polonia en la UE- podría describirse como sigue:

Inmediatamente después de las elecciones legislativas de diciembre de 2015 en Polonia (que pusieron fin a los 8 años de mandato de los liberal-conservadores del ex primer ministro Donald Tusk, actual presidente del Consejo), el partido ganador de los comicios - Ley y Justicia, PiS, por sus siglas en polaco- puso en marcha su anunciado plan de reforma del Tribunal Constitucional (TC).

Efectivamente, la ley de reforma del TC fue aprobada por el Sejm (Asamblea Nacional) el 23 de diciembre. En síntesis, la enmienda de la ley del TC de 1997 introduce las siguientes novedades:

a) Modificación (restrictiva) de la regla de procedimiento en el tratamiento de admisión y señalamiento de asuntos por parte el propio TC («sequency rule»), estableciendo la regla de la procedencia de casos para su posterior enjuiciamiento por el TC;

b) Establecimiento legal de una nueva «regla de mayoría decisoria» de los $2 / 3$ de sus 15 miembros para decidir sobre cualquier asunto, así como la fijación de un previo quorum preceptivo de al menos 13 de los 15 Jueces para poder constituirse y deliberar legalmente. Debe recordarse aquí que el art. 190.5 de la Constitución Polaca requiere tan solamente una «mayoría de votos» para la resolución jurisdiccional de asuntos (entendiéndose desde entonces que se requiere de la «mayoría simple», más votos favorables que en contra). Además, el cuadro orgánico se complementa con el expeditivo nombramiento en el TC de 5 nuevos magistrados con la clara intencionalidad, por parte de la nueva mayoría del partido gobernante PiS en la Sejm, de alterar la hasta entonces imperante correlación de fuerzas en el interior del TC escorando la balanza en favor de posiciones ultraconservadoras en la interpretación de la Constitución.

El historial de antecedentes regresivos de Polonia no se limita al capítulo de reformas normativas. No puede ignorarse en este punto que Polonia fue el primer Estado de la UE en el que se verificaron acciones de complicidad con los «programas de entrega y detención secreta» (secret renditions) autorizados por el Presidente G.W. Bush tras los atentados del $11 \mathrm{~S}$ en EE.UU.

En julio de 2014 el TEDH condenó con una serie de sentencias sucesivas los abusos perpetrados por el Gobierno Polaco en convivencia por la CIA por violación de la prohibición de tortura y trato inhumano y degradante y de la detención secreta. El presidente Kaniskowski reconoció en su momento que, durante los años 2002 y 2003 , se mantuvo en territorio polaco, fuera del conocimiento y del 
escrutino público, una prisión secreta de la CIA que asegurase el objetivo de interrogar «sospechosos» sin constricciones legales ${ }^{29}$.

Pero es seguramente en el ámbito del derecho de familia, y de derechos sexuales y reproductivos, donde Polonia mantiene un historial más intenso y sostenido de desafío al derecho del $\mathrm{CEDH}$, seguido seguramente por sus condenas por violación de la prohibición de discursos y actos discriminatorios (crímenes de odio y actitudes antisemitas).

Por su parte, el sistema judicial polaco también ha sido a menudo sometido a escrutinio en el ámbito del Consejo de Europa (últimamente, por la así denominada «Ley de Procedimiento contra personas con trastornos mentales», autorizando su reclusión en aislamiento en centros cerrados). Los casos de demandantes de refugio y de protección subsidiaria han constituido asimismo casos altamente frecuentes de denuncias contra Polonia ante el TEDH.

En todos estos terrenos, con una u otra intensiad, el Gobierno de Polonia ha opuesto su resistencia a las exigencias derivadas de la integración europea, ya sea obstaculizando o excepcionando el ELSJ (art. 67 a 89, título V, TFUE) en territorio polaco, ya sea interponiendo objeciones a la vinculatoriedad de la CDFUE «con el mismo valor jurídico de los Tratados» (art. 3 TUE), lo que en su momento fue objeto de un Protocolo específico de la modalidad de ratificación por Polonia del Tratado de Lisboa.

\section{El Gobierno de Ley y Justicia: La iniciativa de reforma del Tribunal Constitucional de Polonia}

Partiendo de estas coordenadas, apenas resulta sorprendente que el Gobierno de Polonia haya venido dando durante los últimos meses, abierta y resueltamente, pasos de siete leguas hacia su asimilación en esa senda tendencialmente antieuropea, nacionalista y de tintes ultraconservadores de su «identidad nacional», cuyos antecedentes señala el «espectro que recorre Europa», teñida por una retórica en la que se mezclan tintes victimistas y/o eurófobos, y abrazada hace ya tiempo, como comentábamos antes, por el Gobierno de Orban y de Fidesz en Hungría.

En efecto, desde que se produce la victoria por mayoría absoluta del ultraconservador PiS con el $38 \%$ de los votos, pero reforzada hasta la mayoría absoluta (con un «premio de mayoría»), el Ejecutivo liderado por la primera ministra Beata Szydlo (bajo la indisimulada dirección política de Jaroslaw Kaczynski, hermano superviviente de su gemelo Lech) se ha embarcado sin ambages en

29 Véase a este respecto Carrera, S., Guild, E., Soares da Silva, J. y Wiesbrock, A.: The Results of Inquiries into the CIA's Programme of Extraordinary Rendition and Secret Prisons in European States in Light of the New Legal Framework Following the Lisbon Treaty, Parlamento Europeo, 2015. 
un ciclo de reformas de sentido regresivo, acompañándose para ello de un discurso deslegitimador de las instituciones diseñadas para funciones de control externo (notoriamente, cómo no, los medios independientes y el Tribunal Constitucional...) y de la argumentación de que «el pueblo polaco les ha elegido para gobernar Polonia y llevar a cabo su programa, haciendo lo que ahora está haciendo».

Subyace en este discurso la premisa inaceptable de que la democracia sería una cáscara vacía, forma sin contenido, apenas contraída a la regla de la mayoría sin más. Nunca ha sido verdad que exista nada parecido a una variante «liberal» de la democracia (quiere decir «antiliberal») por lo que la mayoría puede desvirtuar el sustrato del pluralismo político, el equilibrio entre poderes distribuidos policéntricamente y en disposición de compensarse, frenarse y equilibrarse interactiva y recíprocamente, la regla de la prima de derecho y de la Ley democráticamente legitimada por la inviolable dignidad de la persona en la que residiría lo que constitucionalmente podemos denominar «soberanía del individuo» en la esfera irreductible de sus derechos fundamentales.

Pues resulta que no. La democracia en Europa no es, nunca lo ha sido, la «regla de la mayoría» y por la mayoría, sin más: es también, y sobre todo, respeto de la(s) minoría(s), protección y tutela de la función de oposición y garantía de que la oposición puede llegar al gobierno a través de un debate pluralista en una sociedad abierta. Polonia camina resueltamente en la senda de la «democracia iliberal (antiliberal)» preconcebida por Viktor Orban con retórica fanfarrona y confrontacional ante el PE.

En el Pleno celebrado el 19 de enero de 2016, también la primera ministra de Polonia, Beata Szydlo compareció en Estrasburgo en esa misma longitud de onda, con una actitud que mezclaba dolorido victimismo (invocaciones continuas a la singularidad de la «idiosincrasia polaca» y a su «identidad» lesionada y acosada por la ilegítima injerencia europea»), la reiterada denuncia de una «inaceptable práctica» de «doble rasero» o «double standard» («iesto no se lo hacen a otros! ¿Por qué me lo hacen a mí?»), y la reivindicación de un espacio de «soberanía nacional» en claves incompatibles con cualquier obligación de pertenencia a un club cuya razón de ser consiste precisamente en compartir (y ceder) soberanía en aras de una construcción de un espacio supranacional regido por el derecho, cuyo sustento exige la voluntad de acatar y compartir ese ordenamiento jurídico (de nuevo cuño) supranacional provisto de fuentes y reglas propias (primacía, aplicación en forma garantizada y efecto directo y un TJUE) y sobre todo en una Carta de Derechos plenamente vinculante (CDFUE) a la luz de su mismo «valor jurídico» que los Tratados (art.6 TUE) ${ }^{30}$.

30 Cfr. la intervención realizada por la Primera Ministra de Polonia, Beata Szydło, en el debate en sesión plenaria del Parlamento, el 19 de enero de 2016, sobre la situación del Estado de Derecho y las restricciones a la libertad de la prensa en Polonia. 
Ninguna de estas modificaciones es políticamente neutra. Hasta ahora, los asuntos pendientes podían demorarse seis meses, salvo excepcionales circunstancias de urgencia que aconsejaran su reducción a tres meses. La nueva regla obliga al TC a enjuiciar los asuntos por su riguroso «orden de bandeja de entrada» (estricto orden de precedencia cronológica). Además, se establece la potestad del Sejm de revocar (destituir) a los jueces del TC de su mandato jurisdiccional.

Aprobada definitivamente por el Sejm el 23 de diciembre de 2015, y acto seguido aprobada en el Senado el 24 de diciembre de 2015 tras un debate de madrugada, la ley de reforma del TC fue promulgada por el Presidente Andrzej Duda el 28 de diciembre de 2015, en una decisión orientada a provocar y asegurar la consiguiente «parálisis» del TC y la incapacidad de este órgano para continuar ejerciendo su función de garantía de la supremacía y normatividad de la Constitución mediante resoluciones vinculantes para todos los poderes públicos.

En efecto, sometida esta reforma legislativa (operada, a lo que se ve, con lo que en lexicología española llamaríamos «nocturnidad y alevosía») al consiguiente enjuiciamiento del propio TC, cuya composición y funcionamiento alteraba intensamente, esta ley fue declarada inconstitucional y por lo tanto nula en la relevante sentencia dictada por el propio TC el 9 de marzo de 2016. Esta decisión fue adoptada por el Alto Tribunal con una composición (12 miembros) que incumplía el nuevo quórum exigido por la ley cuya constitucionalidad enjuiciada (quórum de 13 miembros), por lo que fue recibida con ostensibles signos de desprecio y desacato por las más altas autoridades del Estado, incluidas la primera ministra Szydlo, el ministro de AA.EE. (Grzegorz Schetyna), el ministro de Justicia (Zbigniew Ziobro) y el propio strongman y líder del PiS, Jarosław Kaczynski.

A la vista de esta importante sentencia, y de su significado en un contexto de conflicto ineterinstitucional, la Comisión Europea resolvería, el 1 de junio de $2016^{31}$, iniciar el proceso denominado «mecanismo de Estado de Derecho» en las tres fases contempladas en el documento en el que se la articula. El objetivo conjunto y final del procedimiento es evaluar el nivel de adecuación de la reforma del TC a la regla europea del Estado de Derecho en conjunción con las restantes manifestaciones regresivas de los llamados «criterios de Copenhague» supuestamente vinculadas al cumplimiento del programa ultraconservador del PiS y, en especial, junto a la reforma del TC, del estrechamiento del control gubernamental sobre los medios de comunicación.

Como era de esperar, visto el antecedente referido en el caso búngaro, también el PE decidió, por medio de un acuerdo adoptado en su Conferencia de Presidentes, incluir en el orden día un debate monográfico sobre esta situación preocupan-

31 Véase el comunicado de prensa de la Comisión Europea de 1 de junio de 2016: http://europa.eu/ rapid/press-release_IP-16-2015_en.htm 
te en torno al caso polaco, con la presencia y participación en el Pleno de Estrasburgo de la PM Beata Szydlo, en su sesión de enero de 2016.

Procede recordar aquí de nuevo que la llamada «Regla del Estado de Derecho» (Rule of Law Framework Mechanism) contempla, desde su adopción formal en marzo de 2014, tres fases procedimentales eventualmente sucesivas. Y como tales fueron explicadas una a una, en el transcurso de aquel Pleno, por el Vicepresidente de la Comisión responsable de Rule of Law (Frans Timmermans).

El primer paso del referido «mecanismo» consiste en la «aclaración objetiva de los hechos en diálogo con el Gobierno polaco» (intercambio de documentación y aclaraciones).

El segundo momento procedimental se corresponde con la adopción de medidas de salvaguarda o de reparación proporcionadas a los problemas detectados y a la amenaza a los bienes jurídicos a proteger.

El tercero, eventualmente, contempla la activación del proceso decisional que puede llegar a conllevar, en última instancia, a la aplicación del art.7 TUE contra un E.M. que se constate que «viola de forma grave y persistente» los valores de la UE (incluye, en último extremo, la suspensión de su derecho de voto en el Consejo).

El trasfondo de alarma política de este procedimiento fue expresado, contundente y polifónicamente, en el Pleno del PE en Estrasburgo, por cuantos intervinientes tomamos la palabra en el debate. La premisa dominante en el debate en el PE es meridiana: todos los EE.MM. - llámese Hungría, Eslovaquia o Reino Unido- deben respetar los compromisos contraídos mediante su adhesión al TUE, en consecuencia con la entrada en vigor del Tratado de Lisboa (TL) y, con ella, de la propia CDFUE.

El Gobierno de PiS responde a una agenda nacionalista y ultraconservadora, de inspiración ultracatólica y antieuropea. Su programa ha sido calificado de auténtico «golpe de Estado» por los portavoces de la oposición. Confrontado abiertamente tanto con la gestión de la emergencia humanitaria y «crisis de refugiados» (en el refractario «grupo de Visegrado») como contra la admisión de ningún tipo de responsabilidad en la admisión de contingentes («cuotas») de «realojamiento» de refugiados dentro de un territorio, el gobierno del PiS se ha situado extramuros de la política europea con una agresión frontal al signo que garantiza la supremacía de la Constitución sobre el poder del Estado.

De hecho, cuando se produce el pronunciamiento del TC, el Gobierno se apresura a descalificarlo con trazo grueso y carga de profundidad.

El Pleno del TC afirma con claridad que la reforma inconstitucional altera sustancialmente el modelo constitucional del TC, restringiendo sus funciones tanto como su independencia y a la postre su eficacia, poniendo en peligro no solo el Estado de Derecho sino la propia democracia y la libertad en Polonia

La reacción del partido Ley y Justicia descalifica sin ambages ni matices al TC, colocándolo fuera del reconocimiento de toda legitimidad, y situando al Gobierno de Polonia en abierto desacato a sus resoluciones por considerarlas 
contrarias a las reglas sobrevenidas que le habían sido impuestas en la propia reforma.

Por su parte, el Consejo de Europa — por la Comisión de Venecia, (Democracy through Law) — alerta en su Informe de los riesgos sistémicos planteados no solo por la reforma obrada en Polonia por su mayoría parlamentaria, sino de la amenaza sistémica que esta situación supone para la integración supranacional europea en materia de derechos ${ }^{32}$.

Empeorando este ya de por sí preocupante cuadro de problemas, el ministro y viceministro de AA.EE. de Polonia responden también, de inmediato, al Consejo de Europa, cuestionando abiertamente la fundamentación y los objetivos «políticos» de su dictamen consultivo, de la Comisión de Venecia, y del propio Consejo de Europa, del que Polonia forma parte — como los restantes EE.MM de la UE_- y atacando personal y políticamente a su Secretario General, el noruego Thorbjørn Jagland.

Detengámonos por un momento en el referido dictamen del Consejo de Europa, en un sintético resumen de sus elementos de análisis.

\section{Informe del Consejo de Europa sobre la reforma polaca}

Efectivamente, como era de esperar, la Comisión de Venecia deliberó (en su sesión plenaria del 11-12 de marzo de 2016) su dictamen sobre la Ley de 28 de junio de 2015 del TC. La opinión de este prestigioso organismo consultivo en materia de Estado de Derecho había sido requerida por carta por el propio ministro de AA.EE. del Gobierno de Polonia, Witold Jan Waszczykowski, para evaluar, concretamente, las referidas reformas del TC sometidas al Sejm el 2 y 15 de diciembre de 2015.

En sus consideraciones generales y análisis de antecedentes, el dictamen de la Comisión de Venecia repasa la cronología de la configuración legislativa del TC polaco. En una exposición sumaria, arranca ésta en 2013, cuando el (entonces) Presidente Komorowski promulgó ya una primera y significativa reforma del TC, y conduce a la reforma completada el 25 de junio de 2015 cuando el Sejm adopta la última versión de la Ley del TC, que entra finalmente en vigor el 30 de agosto de 2015. El 8 de octubre de 2015, en su última sesión antes de las elecciones, el Sejm votó la elección de los 5 jueces que debían reemplazar a los tres salientes el 6 de noviembre de 2015 y a los dos que completaron su mandato en diciembre de 2015. El presidente de la República, para entonces ya Andrzej Duda (en sintonía con la nueva mayoría ultraconservadora del PiS surgida de las

32 Véase el dictamen de la Comisión de Venecia, de 12 de marzo de 2016, sobre las enmiendas de 22 de diciembre de 2015 a la Ley de 25 de junio de 2015 relativa al Tribunal Constitucional de Polonia (CDL$\mathrm{AD}(2016) 005)$. 
elecciones de noviembre de 2015), se negó a ratificar estos nombramientos de los desde entonces llamados «jueces de octubre».

Acto seguido, el Grupo parlamentario del PiS impugnó ante el TC estos últimos nombramientos, forzando también, desde la nueva composición del Sejm (con mayoría absoluta del PiS con la base de un 38\% de apoyo electoral y un «premio de mayoría») la incorporación al TC de magistrados de su línea política e ideológica. A partir de ahí, el Gobierno de PiS y su mayoría absoluta resuelven invalidar esos anteriores nombramientos y sus decisiones a partir de la elección. Desde entonces, la reforma constitucional del TC no ha hecho más que complicarse.

La aprobación por el Sejm de la reforma del TC (Ley del 22 de diciembre) fue a su vez impugnada por la oposición parlamentaria. La sentencia del 9 de marzo de 2016 (K47/15) del TC polaco se pronunció sobre este recurso de inconstitucionalidad, después de haber sometido a trámite su «procesabilidad» en acto de 14 de enero.

a) Fundamentos jurídicos del caso ante el TC Polaco. La Fundamentación constitucional para enjuiciar las leyes reguladoras de la propia configuración de lo jurisdiccional, y de sus modificaciones.

b) Cuestiones de procedimiento: b.1) «Sequency rule», o regla de enjuiciamiento temporal de casos subordinados a la protección temporal y cronológica de su respectiva admisión en la bandeja de entrada del TC; b.2) Quorum de presencia de jueces necesario para la reunión legal del TC: se establece como regla la presencia de al menos 13 de los 15 jueces del total que integran el supremo; b.3) Fijación de una nueva regla de mayoría de 2/3 para la adopción de decisiones válidas por parte del TC; b.4) Establecimiento de un plazo legal mínimo para el enjuiciamiento de casos: tres meses para la audiencia pública y seis meses para la deliberación en pleno.

c) Articulación legal de un nuevo procedimiento disciplinario para la renovación de jueces.

El problema constitucional esencial en esta enconada disputa, como puede colegirse, no residiría tanto en la definición formal de las reglas de «integración» y renovación pautada de los miembros del TC (esto es, la composición del TC), sino en la decisión política de «quién manda» en el TC. Y el partido en el Gobierno, Ley y Justicia, evidencia a todas luces haberse tomado muy en serio esta cuestión nuclear.

Y a esta cuestión subyace otra: la dilucidación de la constitucionalidad o no (esto es, la afirmación o negación de su discutido carácter de regla constitucional) de la pretendida «costumbre constitucional» de «evitar» la elección de nuevos jueces cerca de unas elecciones (alegada por el PiS para deslegitimar a los cinco nuevos «jueces de octubre»).

$\mathrm{Y}$ a las anteriores cuestiones se sobreimpone el problema del principio de «leal cooperación entre los poderes del Estado», y su eventual quebrantamiento en el supuesto litigioso que se somete a discusión. 


\section{Valoración de conclusiones del Informe de la Comisión de Venecia}

El dictamen emitido por la Comisión de Venecia es eminentemente crítico, y advierte contra la arbitrariedad y el abuso de poder de la mayoría parlamentaria. Se desprende de la opinión del organismo consultivo del Consejo de Europa una teoría de la democracia constitucional claramente resuelta a desactivar la burda identificación de la democracia constitucional con la «regla de la mayoría». No lo es. Tanto la acumulación de reformas parciales sobre la jurisdicción constitucional, como su sobreimposición en su ritmo acelerado de tramitación parlamentaria, redundan en la restricción o atropello de los derechos de participación de las minorías en el procedimiento legislativo, con la consiguiente vulneración a las reglas y métodos que hacen reconocibles a una democracia pluralista.

El examen culmina con una severa crítica a las declaraciones de desacato a las sentencia del TC, en vista de lo resuelto y de la declarada voluntad política del Gobierno del PiS de desoír y despreciar el pronunciamiento jurisdiccional, incumpliendo el fallo, descalificándolo in toto como un pronunciamiento ilegítimo propio de «tertulia de jueces», pero no de un órgano jurisdiccional, e incluso negándose a publicarlo en el Boletín Oficial del Estado (la Gazzette que garantiza la publicidad de las sentencias de los tribunales de Justicia).

\section{EL CASO DE POLONIA ANTE EL PARLAMENTO EUROPEO}

Vistos estos antecedentes y materiales en presencia, los documentos de trabajo del PE aportan, también, por su parte, ideas interesantes sobre la vinculación histórica de la construcción de la ley, la separación de poderes, el respeto a los derechos fundamentales, la protección de las minorías y su tutela judicial. Las referencias constitucionales en los arts. 2, 3 (párrafos 2 y 5), 5 y 6 del TUE, se complementan con la lectura del art. 7 y con la entrada en vigor de la CDFUE revestida del «mismo valor jurídico de los Tratados» (art.6 CE), especialmente en lo tocante a sus disposiciones relativas a la delimitación de su ámbito de aplicación, cláusula de prevención del abuso del derecho y su conjugación con los niveles nacionales de protección de los mismos derechos fundamentales consagrados en la Carta (arts. 51 a 54 CDFUE).

Merecen atención también los mecanismos y procedimientos de garantía de derechos y libertades públicas de los ciudadanos europeos (comprendidos, por supuesto, los ciudadanos polacos), incluidos los jurisdiccionales. Se alude con esta referencia a una variedad de instrumentos, desde el procedimiento de infracción por incumplimiento del Derecho europeo (arts. 258 y 55 TFUE) hasta el recurso ante el TEDH (pendiente todavía el cumplimiento de la obligación de la UE de adhesión al CEDH de 4 de noviembre de 1950 y sus Protocolos, incluida su sujeción a la jurisdicción al TEDH, art 6 TUE). No obstante, resulta innegable que los remedios judiciales (judicial remedies) no están al alcance de cualquiera (discriminación 
económica: asesoramiento legal, resistencia al paso del tiempo, costes de litigación) aunque el dispositivo esté ahora disponible tanto para personas físicas como para poderes públicos (EE.MM. contra otro EE.MM.) o para las instituciones europeas.

Se hace notar, a este respecto que el TUE prevé el supuesto de que un Estado miembro suscite una amenaza «grave y persistente» de violación del Derecho... pero no que este incumplimiento pueda provenir de una institución de la UE.

De modo que la reflexión política orbita más en la posibilidad de «reforzar» o «perfeccionar» los llamados «marcadores» (Scoreboard) y los procedimientos de «diálogo» e «intercambio de información, cartas, aclaraciones y opiniones» entre la Comisión Europea y los EE.MM (o el Estado miembro concernido), procedimientos diseñados para asegurar el carácter ordinario del escrutinio europeo sobre la adecuación de los EE.MM y de sus actuaciones a lo dispuesto en el TUE y en la CDFUE (a través del llamado Rule of Law Mechanism).

En efecto, para asegurar la viabilidad del complejo entramado de supuestos $\mathrm{y}$ consecuencias judiciales previsto en el art. 7 TUE (aun cuando resulta notoriamente sobreactuada su frecuente adjetivación como la «opción nuclear», a la vista de su inexistente poder de disuasión), las instituciones europeas han arbitrado el llamado Mecanismo de Marco del Estado del Derecho (State of Law Framework Mechanism) (COM2014/0158 de marzo de 2014), articulando tres fases:

a) Evaluación de la Comisión de la situación planteada por la actuación del Estado miembro concernido;

b) Recomendación de la Comisión;

c) Seguimiento de las Recomendaciones y eventual aplicación del art. 7 TUE.

Vista la dificultad de las acciones judiciales ante el TJ (con todas las salvarguardias y garantías contempladas en el art. 258 TUE), el Consejo decide estipular un «Diálogo para promover y salvaguardar el Estado de Derecho» (Conclusión del Consejo del 15 de diciembre de 2014).

Por su parte el PE ha resuelto (Conferencia de Presidentes, órgano rector del $\mathrm{PE}, 2012$ ) adoptar regularmente un así llamado «Informe anual sobre la situación de los Derechos Fundamentales por el $P E »^{33}$, con un examen seccionado por asuntos temáticos, y complementario a su vez del Informe Anual sobre la Aplicación de la CDFUE, que desarrolla la Comisión ${ }^{34}$, y el EU Justice Scoreboard (Cuadro de Indicadores de la Justicia en la UE) ${ }^{35}$ puesto en marcha por la entonces Vicepresidenta y Comisaria de Justicia Vivianne Reding.

33 Véase la Resolución del Parlamento Europeo, de 8 de septiembre de 2015, sobre la situación de los derechos fundamentales en la Unión Europea (2013-2014) (2014/2254-INI-).

34 Véase la Comunicación de la Comisión sobre la estrategia para la aplicación efectiva de la Carta de los Derechos Fundamentales por la Unión Europea, de 19 octubre 2010 (COM(2010) 573 final).

35 Véase la Comunicación de la Comisión al Parlamento Europeo, al Consejo, al Banco Central Europeo, al Comité Económico y Social Europeo y al Comité de las Regiones sobre el cuadro de indicadores de la 
Para completar la caja de herramientas disponibles, no puede ignorarse el papel de la Comisión de Peticiones del PE (en donde se sustancia el derecho de petición como herramienta política de la ciudadanía de la UE, art. 277 TFUE), espacio donde se debaten a menudo alejadas incidencias y problemas de respeto y garantía de los derechos de los ciudadanos en los EE.MM (a «petición» de personas o colectivos afectados). Ni tampoco el importante papel desempeñado por la Agencia de los Derechos Fundamentales (FRA, con sede en Viena), organismo vinculado a la «constelación» de la Comisión LIBE, de la que dimanan regularmente informes documentados acerca del estado de los derechos fundamentales y las amenazas que se ciernen sobre ellos en la UE, con especial atención a la protección de minorías frente a la discriminación y frente al discurso del odio (bate speech) a LGBT, Roma, judíos (antisemitismo) y minorías religiosas ${ }^{36}$.

Como tampoco, finalmente, puede ignorarse aquí la incardinación de la UE en la comunidad internacional y en las agencias especializadas de la ONU para la preservación del derecho de personas vulnerables (ACNUR, UNICEF, Consejo de DD.HH de la UE...).

En respuesta a todos estos retos, las propuestas y recomendaciones que emanan de los trabajos del PE comprenden las siguientes opciones (todo ello desarrollado por experiencias ya encuadradas en las jurisprudencias del TJ, del TEDH y de los TT.CC y sistemas judiciales de los EE.MM, en lo que viene conociéndose como «diálogo de jurisdicciones» en la construcción europea):

a) Refuerzo de la supervisión ex ante de los parámetros de adecuación de la legislación de los EE.MM a los derechos consagrados en la CDFUE (Informes anuales por país, Country Reports, y sectorializados por materias y derechos elaborados por la Agencia Europea de Derechos Fundamentales, la FRA, con sede en Viena);

b) Perfeccionamiento y refuerzo del Rule of Law Framework Mechanism orientado a superar el «Copenhagen Dilemma» puesto de manifiesto ya en el Informe Tavares (primer EP Report sobre Hungría);

c) Reanimación y profundización del diálogo estructurado y cooperativo entre el PE y los Parlamentos Nacionales (previsto y ya ejercitado en el ámbito del GCSJ), incluyendo el tratamiento de los procedimientos de infracción por violaciones de los derechos protegidos por la CDFUE ante el TJUE (art. 258 TFUE);

d) Examen parlamentario de la evaluación de la jurisprudencia del TJ en aplicación de la CDFUE. Desde un primer reconocimiento de las limitaciones impuestas por los artículos de la CDFUE, que encuadran su apli-

\footnotetext{
justicia en la UE: una herramienta para promover una justicia efectiva y fomentar el crecimiento, de 27 de marzo de 2013 (COM/2013/0160).

36 Véase, al respecto, el correspondiente Informe sobre los derechos fundamentales 2016. Dictámenes de la FRA, Agencia de los Derechos Fundamentales, 2016.
} 
cación (arts. 51 a 54 CDFUE), el TJ ha ensanchado su capacidad de enjuiciamiento del derecho derivado de la UE y de la legislación de los EE.MM. en función de su compatibilidad o no con los derechos de la Carta, enfatizando así su valor jurídico como parámetros de validez del Derecho europeo (Data Retention case) o del Derecho nacional de los EE.MM., (enjuiciamiento europeo y declaración por el TJ de la incompatibilidad con el Derecho europeo, Directiva de Protección de los Consumidores, de la legislación procesal española de procedimiento judicial ejecutivo hipotecario...) incluso cuando el legislador nacional prevé hipotéticamente «un nivel más alto de protección» siempre que imponga un obstáculo a la aplicación efectiva y uniforme del derecho europeo (así, caso Melloni en relación con el alcance vinculante y de la efectividad de la Orden Europea de Arresto);

e) El objetivo sigue siendo el de reforzar el sometimiento del Estado y de poderes públicos al standard europeo del Estado de Derecho, asegurar la independencia del TJ y la imparcialidad del Ministerio Fiscal (evitando así la instrumentalización política de la acción penal al servicio del Gobierno para perseguir oponentes, rivales electorales y/o adversarios políticos, fabricando contra ellos investigaciones o acusaciones...), de protección de las minorías (y la función de oposición, que debe ser tutelada con una disciplina jurídica específica), así como la pluralidad de los medios informativos (media pluralism, en un paisaje que suscita creciente preocupación y no solo entre los EE.MM. de más reciente adhesión, como ejemplifica la concentración de medios en manos de Berlusconi en Italia).

Finalmente, se propone también institucionalizar el Debate (anual) paneuropeo sobre la «democracia, el Estado de Derecho y los DDFF», desarrollando experiencias y prácticas ya previamente ensayadas por las Conferencias de Presidentes de Parlamentos de la UE (desde 1981), la Conferencia de Órganos especializados en Asuntos Comunitarios de los Parlamentos de la UE (COSAC desde 1989) y por las Reuniones Interparlamentarias Conjuntas (Joint Interparlamentary Meetings) especialmente intereses en el ámbito del ELSJ (desde 2009-2010).

Corroborando lo anterior, resulta expresiva la (cada vez más frecuente) comparación y paralelismo de la dinámica establecida en la que se conoce como «Semestre Europeo» respecto de la insuficiencia de mecanismos orientados a preservar la calidad de la democracia y las reglas del Estado de Derecho en la UE. En efecto, establecido el mecanismo del «Semestre europeo» en 2011, en el contexto de la Gran Recesión (la gran crisis económica y financiera del 2000), se pretende institucionalizar un «diálogo» y una «alerta temprana» en el control preventivo de la planificación presupuestaria y de cuentas públicas entre la UE y los EE.MM. Su sistema de control periodizado incluye un debate en que participan Comisión, Consejo, PE y los EE.MM. para «asegurar los objetivos de la Estrategia 2020 y el Pacto de Estabilidad y Crecimiento». 
Ello implica sujetarse a las interacciones interparlamentarias anuales entre los EE.MM y el PE al objetivo de asegurar una coordinación de políticas y de sus legislaciones en este ámbito temático, y se propone transportar a la evaluación, escrutinio y prevención de desviaciones respecto de la observancia de los parámetros definitorios de la democracia, el Estado de Derecho, el imperio de la ley y los derechos fundamentales, haciendo valer en ello cuantos documentos de apoyo, opiniones de cualificados expertos, asesoramiento externo (modo Comisión de Venecia), Agencias especializadas (FRA), Recomendaciones documentadas (Comisión) y Resoluciones (documentación del PE) sean de utilidad.

Así el acervo de conocimiento especializado y la cooperación interinstitucional se orientan a producir ex ante una evaluación de impacto sobre la calidad democrática e institucional.

\section{REFLEXIONES CONCLUSIVAS: RETROCESOS DEMOCRATICOS Y DILEMAS DE COPENHAGUE. EL CASO POLACO EN CONTEXTO}

La preocupación a propósito del bajo estado de forma de la regla del respeto por la primacía del Derecho (Rule of Law) y los derechos y libertades (Fundamental Rights) en los EE.MM. de la UE no ha hecho sino acentuarse en los últimos años.

Un conjunto de concausas entrelazadas entre sí, la «gran ampliación» y la pérdida de consistencia y homogeneidad en los respectivos niveles de consolidación y maduración institucional y democrática de los recientes EE.MM, la Gran Recesión, el empobrecimiento de los servicios sociales, la austeridad, los «recortes» y el aumento de la desigualdad y el malestar social, la deslegitimación de la construcción europea, el auge del nacionalismo y el populismo asociado a los discursos xenófobos y estigmatizadores de determinadas minorías y/o de los extranjeros, sin duda han contribuido a este empeoramiento acusado de la calidad democrática.

Al lado de este estado de opinión se han multiplicado los estudios especializados (doctrinales y académicos), los documentos de trabajo elaborados en el seno de las instituciones (informes parlamentarios), así como en think tanks especializados o Agencias de la constelación europea del Espacio de Libertad, Seguridad y Justicia.

Esta rica variedad de aportaciones documentales describe con claridad algunos hilos conductores. Se trata de elementos comunes que pueden sintetizarse como sigue:

a) En primer plano, proporcionan fundamentación adecuada a la necesidad estratégica de que la UE refuerce su capacidad de examen (escrutiny) del nivel de sujeción de los EE.MM. a los valores y principios de la primacía del Derecho (Rule of Law), 
b) La primera premisa es la de que la UE es, ante todo, una «Comunidad de valores» regida por el Derecho (art. 43 TUE). En cuanto Comunidad se construye solo de reconocimiento mutuo de la homogeneidad y compatibilidad de los ordenamientos jurídicos e instituciones de los EE.MM (Parlamentos, Poderes judiciales, ministerios públicos, Tribunales constitucionales...) y sobre la confianza mutua. Por lo mismo, el deterioro del Estado de Derecho en un Estado miembro afecta a todos los demás. Tanto los EE.MM. en su conjunto como la propia UE deben poder participar en un mecanismo fiable de evaluación continua. Complementariamente, la aproximación doctrinal a la UE como un case study de lo que ha dado en llamarse «Constitucionalismo multinivel» exige (no solo aconseja) la aceptación de un juego de «pesos y contrapesos» (Checks $\mathcal{E}$ Balances) en el que los demás socios condicionen los reequilibrios de cada uno;

c) La segunda premisa se describe ya clásicamente como la formulación del «dilema de Copenhague»: alude esta imagen metafórica a la contradicción entre las condiciones democráticas que deben verificarse con el filtro de acceso al club (protocolizados con detalle) y su disolución en la ausencia de los controles ex post a partir de la adhesión. Ante ese «dilema», cunde la convicción de que es preciso afirmar un cierto nivel de exigencia de «reglas de comportamiento en la pertenencia del club» (club bebaviour), en modo que sea posible objetivar el reproche a los EE.MM. que adopten medidas legislativas o decisiones políticas en una dirección regresiva (la concentración mediática en la Italia de Berlusconi, la llamada «Ley Mordaza» en España, entre otros objetos polémicos...).

Resulta necesario, ante todo, poner en común de manera comprensiva (bolistic approach) los instrumentos actualmente disponibles para la reparación de eventuales retrocesos en democracia y derechos y libertades:

a) Por un primer lado, están los procedimientos judiciales:

- ante la judicatura y TC de los EE.MM;

- ante el TEDH (pendiente aún la adhesión de la UE al CEDH mandatada por el art. 6 TUE, desatendida por la sentencia del 14 de diciembre de 2015 del TJ);

— ante el TJ (procedimeintos de infracción e incumplimeinto, art. 258 y 11 TFUE).

b) En su correspondiente plano, figuran los procedimientos específicamente constitucionales: Comunicación de la Comisión (el llamado «Mecanismo del Estado de Derecho») y el así denominado Diálogo estructurado sobre el Estado de Derecho y los derechos fundamentales (Comisión, Consejo, PE). 
La conclusión política más relevante que hasta ahora se desprende de los debates sostenidos en el PE es singularmente meridiana: el PE no es — contrariamente a la retórica nacionalista cada vez más socorrida - ninguna «potencia extranjera», ni actúa —ni en Hungría ni en Polonia ni en ningún Estado miembro- como una nave espacial venida del espacio exterior: representa al pueblo húngaro tanto como al pueblo polaco puesto que ambos forman parte del pueblo europeo. Hungría y Polonia son Europa y la UE es Hungría y Polonia.

Afirmando lo anterior, el PE se posiciona del lado de la ciudadanía húngara y polaca y sus derechos reconocidos como ciudadanos europeos en la CDFUE.

Si no se comprende esto, nunca debieron haberse suscrito las reglas del club europeo: tal y como se ha expresado en el curso de los debates sostenidos en el PE, «EU cannot remain silent about the Putinization of Hungary (or Poland) any longer».

Mientras hoy la Eurocámara pide sanciones para el Gobierno de Orban y desautoriza su comportamiento, los conservadores europeos (Congreso del PPE) aplaudían la actuación del primer ministro húngaro ante la crisis de los refugiados y ovacionaban su mensaje insolidario de tinte xenófobo en Madrid afirmando que «los refugiados se mueven como un ejército» y que no se les puede dar a acceso a «una vida europea»...

Vistos los elementos de juicio expuestos hasta aquí, resulta imperioso constatar la debilidad e insuficiencia de los dispositivos actualmente disponibles. Para empezar, procede constatar la dificultad de que los actores institucionales (Consejo, Comisión, Parlamento) lleven, hasta el final, con todos los requisitos procedimentales y mayorías reforzadas requeridas, su determinación de intervenir a cualquier Estado miembro que desafíe los parámetros a que venimos refiriendo.

La Comisión Europea es consciente de las cuotas de activación del art. 7 del TUE. El PE aparece recorrido por la contradicciones de las afinidades cruzadas entre sus filas políticas (los socialistas protegen a Victor Ponta en Rumania y el PPE a Victor Orban). Pero particularmente el Consejo deberá asumir el coste de construir una decisión por unanimidad contra un Estado miembro (excluido el Estado afectado por la decisión) y luego una mayoría cualificada (2/3) para la adopción de las eventuales sanciones (que puede incluir la retirada de su derecho de voto en el Consejo).

Además se repiten recurrentemente las mismas alegaciones autoabsolutorias en clave de objeción política a la eventual activación del art. 7 TUE. De un lado, la intolerancia hacia una eventual «intrusión» en la «gobernación» de un Estado miembro (su «idiosincrasia», su «identidad racional»...). De otro, se afean sistemáticamente los «dobles raseros» («¿Por qué a mí?», «¿La tienen tomada conmigo?»). A la postre, se alega políticamente que la intervención de la UE sería «contraproducente» en la medida en que «meta sus narices» en los «asuntos internos» de un Estado miembro (!!!), el único resultado será «más nacionalismo» (reactivo) contra la injerencia de la UE y «más populismo» (reaccionario) escorado a la eurofobia. 
Desde el plano institucional, los procedimientos actuales se prestan a flancos de crítica acerca del decalage entre las «condiciones de accesión» y las de «pertenencia al club». Además la ausencia de estándares homogéneos de «examen» o de «escrutinio» redunda en protestas de «desigualdad» (double standards).

Por ello mismo, las ventajas de establecer una posible arquitectura permanente se perfilan como evidentes: se trataría así de establecer parámetros objetivados, con la introducción de un sistema de alerta temprana... Es en este espacio de reflexión donde ha cobrado progresivamente cuerpo el modelo de «gobernanza macroeconómica» propuesto a través del dispositivo de diálogo interinstitucional que ha dado en llamarse «Semestre Europeo» (control preventivo europeo de la planificación presupuestaria de las cuentas públicas de los EE.MM.), los caracteres compatibles serían sucesivamente:

a) petición de aclaraciones;

b) protocolización;

c) evaluación interinstitucional;

d) aplicación preventiva y correctora de desviaciones frente a la eventualidad de ulteriores estadios de transgresión de valores y principios fundacionales de la UE.

Este control preventivo (complementario al de la fase de imposición de sanciones) podría desarrollar la experiencia de la Justice Score Board (un Rule of Law Scoreboard) que se extendería a la evaluación de los niveles de protección de los derechos fundamentales o desviación respecto de determinados parámetros de mediación y control de la corrupción. Evitaría las quejas recurrentes de «inequidad» (double standards) y permitiría, al mismo tiempo hacer valer las enseñanzas (y reglas) del Derecho comparado. En este punto podría incluso reproducirse la prestigiosa metodología de la «Comisión de Venecia» en el Consejo de Europa (red de expertos, tratadistas, analistas y magistrados constitutivos), con un valor reforzado para asegurar el nivel de respeto y observancia de sus opiniones. Los efectos deberían tender a la «exposición» del Estado miembro y su evaluación constitucional y legislativa. La aspiración colectiva debería apuntar a emitir con claridad el mensaje de que la UE está dispuesta a hacer lo necesario («whatever it takes, whatever is necessary») para asegura la observancia de la Rule of Law y Fundamental Rights (en otras palabras, Draghi Doctrine en materia de calidad democrática y valores europeos compartidos).

Nada de lo anterior será, sin embargo, suficiente. En última instancia, todo depende de ese intangible factor que más cuestionado se encuentra hoy: la voluntad política. La voluntad de integración supranacional europea. La voluntad de los EE.MM. de permanecer vinculados por la «regla del club» y la permanencia en el mismo. Hasta la fecha, lamentablemente, los Gobiernos nacionales han mostrado nula predisposición a actuar «contra» otro «EE.MM.» (temen su propio turno en esa espiral de expiación). La debilidad de la Comisión Europea ante 
el Consejo le impide actualmente siquiera tantear la aplicación del art. 7 TUE, de modo que la capacidad de disuasión de la «bomba nuclear» pierde toda efectividad con la medida en que la propia «disuasión» pierde toda credibilidad.

Un poderoso factor de deslegitimación de la UE deriva precisamente del contraste —insoportable para muchos — entre la determinación con que la UE persigue y sanciona a los EE.MM. que incumplen la prohibición de «déficit excesivo» o «desequilibrio excesivo» de sus cuentas públicas... y la laxitud con que consiente las regresiones más groseras de las reglas del Derecho y de calidad democrática (pluralismo político, medios independientes, justicia constitucional). Este contraste ha sido muchas veces denunciado enérgicamente en los debates y Resoluciones del PE. Por lo mismo, corregir esta situación podría contribuir significativamente a relegitimar la UE.

Con todo, para modificar sustancialmente la insatisfactoria situación actual, sigue siendo precisa (y desde luego aconsejable) una reforma de los Tratados de la UE. Pero mientras siga ahí la regla de la unanimidad exigida por el art. 48 TUE para la modificación de los Tratados, seguirá siendo dificilísimo esperar un cambio real del statu quo actual. Introducir sanciones más duras (en un gradiente a explorar), incluyendo la eventualidad de la «expulsión» de un Estado miembro persistentemente incumplidor (con violaciones graves de la primacía del Derecho o los derechos fundamentales), o la atribución de recursos judiciales directos para denunciar este incumplimiento por parte de un Estado miembro ante el T.J. son elementos del debate habituales en el PE.

Finalmente un criterio político es asimismo necesario. Simplemente no es verdad que los ciudadanos europeos (500 millones en 28 EE.MM.) hayan llegado a ser indiferentes ante los retrocesos de la democracia en la UE. They care, they really care. They do! ... Y contrariamente a lo que se dice y se escribe demasiado a menudo, no existe ninguna evidencia de que los electores en los EE.MM premien a los gobiernos que se enfrentan con la UE con una retórica agresiva cuando las instituciones se preocupan por la calidad democrática o de los derechos en ese país... y castiguen a los gobiernos que atienden sus obligaciones europeas, incluida la regla de solidaridad (ignorada y desechada a todo lo largo de la mal llamada «crisis de los refugiados» y su emergencia humanitaria). Es preciso, ante todo, un mecanismo ordinario de examen y escrutinio de cualquier paso o medida (potencialmente) lesiva de la democracia y de los eventuales retrocesos contra la regla del Derecho y el imperio de la ley. En última instancia, la adopción de un enfoque positivo en la dirección adecuada (y de efectos potencialmente formidables) depende de la voluntad política de los EE.MM y de las instituciones, pero también del empuje de una ciudadanía europea exigente, consciente de sus derechos (como europeos) sociales a su círculo concéntrico de identidades compatibles en un espacio público europeo de escala supranacional (el progreso de una ciudadanía activa a un constitucionalismo multinivel que no desmerezca las conquistas del constitucionalismo en los EE.MM., con todas sus vicisitudes históricas). 
Vaya por delante mi convicción de que esta es la única alternativa ante la agresiva y rampante pujanza del populismo reaccionario y del nacionalismo antieuropeo, teñido de populismo, condicionando así una interpretación ultraconservadora de la orientación histórica de la construcción europea.

Hemos repasado las muy abundantes elaboraciones doctrinales preocupadas en el deterioro de la democracia en la UE y la dificultad estructural para descansar en el dispositivo del art. 7 TUE. Hemos sintetizado el marco legal y político. Y ofrecido una visión sumaria de los mecanismos de la UE (valores, principios, soft law), mecanismos de política exterior y su difícil aplicación (horizontales y verticales; en las escalas nacionales y europea e internacional contra la regla de la subsidiariedad).

Hemos atendido también a algunos de los case study más llamativos de este deterioro de la democracia en la UE: Hungría, Rumanía, Bulgaria... y nos hemos detenido en Polonia.

Hemos subrayado la importancia de la regla del reconocimiento recíproco y confianza mutua. $\mathrm{Y}$ hemos propuesto alternativas para superar esas dificultades en perspectiva de futuro.

La conclusión relevante es que nunca ha sido verdad en ningún Estado miembro - tampoco en la UE- que pueda contraponerse la democracia (los votos) a la ley (democráticamente legitimada) ni a la Constitución. Porque ninguna democracia ha sido nunca «ley de la mayoría» sin más; la democracia es, sobre todo, respeto a las minorías, a los derechos fundamentales que sustentan la dignidad inviolable de todas las personas (del individuo) y garantía a la función de la oposición política. Y democracia es respeto a la regla de juego establecidas en leyes democráticamente legitimadas.

El PiS (Ley y Justicia) obtuvo la presidencia de la República Polaca el 24 de mayo de 2015 y una mayoría absoluta (un premio de mayoría: $38 \%$ de los votos) el 28 de octubre. Inmediatamente procedieron al desmantelamiento del TC (modificando su composición y sus reglas de decisión), así como a la intervención masiva de los medios de comunicación (regubernamentalización de radio y TV públicas). Demasiado burdo, brutal, grosero. Muestra, una vez más, la tentación de los partidos totalitarios y autoritarios a controlar la justicia y los medios de comunicación.

Es singularmente grave la situación del TC polaco en el momento presente. La tensión y el enfrentamiento entre el TC y el Parlamento polaco (Sejm) ponen de manifiesto un conflicto institucional que evidencia el retroceso de los parámetros de democracia en la UE.

El conflicto enfrenta legalidad (nombramiento de magistrados en la anterior legislatura) y legitimidad democrática (sentencias dictadas por el TC, y nombramientos realizados por el Presidente de la República y descalificación de jueces tras la resolución del Tribunal).

La Comisión Europea se enfrenta tanto a la situación real como a la limitación de la respuesta: art. 7 TUE y mecanismo a tres fases del «Estado de Dere- 
cho». El ministro de Interior polaco — Zbigniew Ziobro- ha confrontado especialmente con la Comisión (comisario Günther Oettinger y Vicepresidente Frans Timmermans) con la habitual retórica de «intolerable injerencia en la soberanía de Polonia».

Pero la UE sigue siendo, esencialmente y sobre todo, soberanía compartida. Quien no la entienda no ha entendido nada. Una UE sin valores y normas y reglas jurídicamente vinculantes sería irreconocible e irrelevante.

Las reglas definitorias del Estado de Derecho son un componente esencial del modelo europeo: pesos y contrapesos, equilibrios y frenos entre poderes y contrapoderes. Todo cruje cuando ciudadanos europeos quedan desamparados frente al declive de estas reglas en algún Estado miembro por impotencia o inanidad de las instituciones europeas.

No es verdad, en fin, tampoco, que pueda contraponerse Polonia, Hungría - o España, Italia, Francia, Dinamarca o Reino Unido-a la UE, o a su Derecho. Se es polaco y europeo, húngaro y europeo, español y europeo. Identidades compatibles. Y solo hay democracia en la UE cuando se cumple un Derecho que garantiza en igualdad —esto es, con igual dignidad y con igual libertad- las identidades múltiples, abiertas y compatibles de los ciudadanos europeos.

\section{*** *}

TitLE: The case of Poland in the EU: democratic setbacks and the regression of the Rule of Law, the «Copenhaguen dilemmas»

ABstract: During the European legislatures 2009-2014 and 2014-2019 the EU has witnessed the challenge posed by the alarming signs of deterioration and decline of democracy in the EU. Not by chance this trend has coincided with the immersion of the Union in the worst crisis in its history that began in 2008 and has been called the "Great Recession» of the EU or the European "glaciation». Over this period Hungary has been the best example of democratic backsliding in the EU but Poland has shown an equally worrying deterioration lately. Yet these are not, unfortunately, isolated cases but there is rather an increasingly widespread trend in Europe that has received, depending on the context, the name "putinization» or «orbanization». The present article recounts the constitutional deterioration experienced by those two countries and the initiatives that have been launched from the EU to follow-up and contest those processes. The article emphasizes the "anti-liberal» or «iliberal» features that characterize these democracies as well as those marks inherent to the rise of nationalism and intolerance and puts them in relation to other historical processes of democratic erosion in Europe, focusing on the dialectic democracy vs populism. The article also exposes the conflicts stemming from the so-called "Copenhagen dilemma" and the rise of the extreme right across the EU and stops in some concrete cases such as the restrictions on the rights of refugees in Denmark or the limitations which have occurred in recent years in the field of civil liberties in Spain. The article concludes that this deterioration is linked to the "great enlargement", which involved the accession to the EU of the Eastern European countries against the backdrop of a relentless financial and economic crisis that rapidly became in a social crisis and a truly crisis of values as a result of the austerity policies imposed by an unsatisfactory bandling of the crisis itself. This has resulted in a challenge to the very idea of European integration coming from different ideological fronts. The article finally stops on the European response to the democratic backsliding described before by reaffirming its fundamental values and by enhancing their protection by implementing new mechanisms to ensure that the quality of democracy and the rule of law in the $E U$ is improved complementing the national systems of judicial protection of fundamental rights legal common to the constitutional traditions of the EU Member States. 
RESUMEN: Durante las legislaturas europeas 2009-2014 y 2014-2019 la UE viene asistiendo al desafío planteado por los alarmantes signos de deterioro y retroceso de la democracia en la UE. No por casualidad esta tendencia ha coincidido con la inmersión de la Unión en la peor crisis de su bistoria, que arrancó en 2008 y ha venido en llamarse la «Gran Recesión" de la UE o la "glaciación» europea. Hungría ba sido durante este período el caso más paradigmático de las derivas antidemocráticas -restricciones del pluralismo político e informativo, de la independencia judicial y de la jurisdicción del TC-experimentadas por países de la UE. Pero, recientemente, Polonia ha dado muestras de un deterioro igualmente preocupante. Con todo no se trata, desgraciadamente, de casos aislados sino una tendencia cada vez más generalizada que ha recibido, según los contextos, el nombre de «putinización» u «orbanización» de Estados miembros de la UE. El presente artículo bace un recuento de los deterioros constitucionales sufridos por esos dos países y de las iniciativas que desde la UE se han puesto en marcha para seguir y dar respuesta a esos procesos. El artículo hace bincapié en los rasgos «antiliberales» o «iliberales» que caracterizan dichas democracias, así como los inherentes al auge del nacionalismo y la intolerancia y los discursos del odio, y los pone en relación con otros procesos históricos de erosión democrática en Europa, incidiendo en la dialéctica democracia vs populismo. El artículo plantea, asimismo, los conflictos que se derivan del denominado "dilema de Copenhague» y del auge de la extrema derecha a lo largo y ancho de la UE y se detiene en algunos casos como el de las restricciones de derechos a los refugiados en Dinamarca o de los retrocesos habidos en los últimos años en derechos y libertades públicas en España. El artículo concluye que los deterioros descritos están vinculados a la "gran ampliación», que supuso la adhesión a la UE de los países del Este, con el telón de fondo de una crisis económica y financiera devenida, en poco tiempo, en crisis social y de valores como consecuencia de las políticas de austeridad impuestas por un manejo insatisfactorio de la propia crisis. Ello ha redundado en una impugnación de la propia idea de construcción europea desde diversos frentes ideológicos. El artículo se detiene, finalmente, en la respuesta europea a las mencionadas derivas a través de una reivindicación de sus valores fundantes y de una protección reforzada de los mismos mediante la implementación de nuevos mecanismos que velen por la calidad democrática y del Estado de derecho en la UE como complemento de los procedimientos judiciales de tutela de los derechos fundamentales comunes a las tradiciones constitucionales comunes de los Estados miembros.

KeY words: Poland, European Union, crisis of Democracy, Copenhagen Dilemmas.

Palabras Clave: Polonia, Unión Europea, crisis de la democracia, dilema de Copenhague.

FECHA DE RECEPCIÓN: 15.06.2016 FECHA DE ACEPTACIÓN: 27.07.2016 